\title{
COMPARISON OF XENON LAMP-BASED AND \\ LED-BASED SOLAR SIMULATORS
}

\author{
by \\ Gregory Patrick Leary
}

A thesis submitted in partial fulfillment of the requirements for the degree

\author{
of \\ Master of Science \\ in \\ Electrical Engineering \\ MONTANA STATE UNIVERSITY \\ Bozeman, Montana
}

April, 2016 
CCOPYRIGHT

by

Gregory Patrick Leary

2016

All Rights Reserved 


\section{ACKNOWLEDGMENTS}

I would like to acknowledge the commitment and support of my family in allowing me to experience this education and wonderful place. My wife, Cindy Leary, son Quinn Leary, and daughter Mae Leary have made this journey a present pleasure. Also, my Parents, Dean and Gail Leary, my sister, Amy Leary, and my sister Angie Hornby and her family Jake Hornby, Logan Hornby and Baylor Hornby have encouraged, shared, and joined in this journey, helping us in anyway they could. I am thankful to and for each of you.

I want to also gives a special thank you to my mentor Dr. Todd Kaiser for providing me with the numerous opportunities in this program; to Gene Kuntz and Dr. Gregg Switzer at ILX-lightwave who made this project possible; to my graduate committee Dr. Joe Shaw and Dr. Hashem Nehrir who were instrumental in my education in the department, to the electrical engineering graduate students for their generously in sharing time, conversations, resources, and ideas; to Dr. Phil Himmer and the Montana Microfabrication Facility for their support in the cleanrooms; and finally to the electrical engineering department for the opportunity to be a graduate student.

Find fun and live a great story. 
TABLE OF CONTENTS

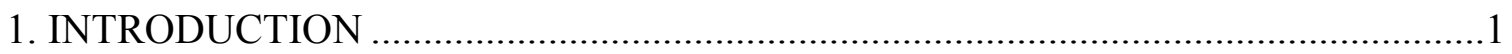

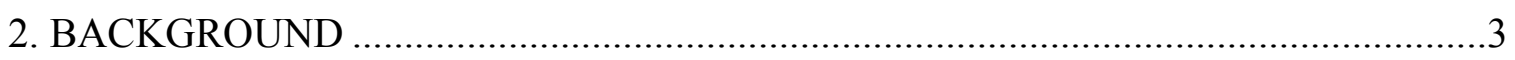

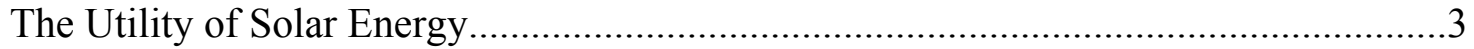

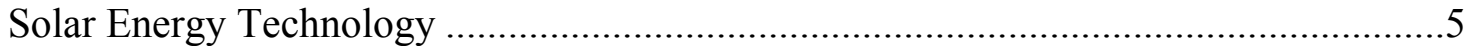

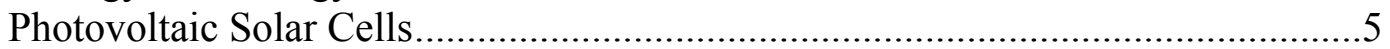

Solar Thermal Technology ………….........................................................

Thermoelectric Technology .........................................................................

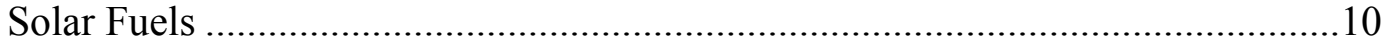

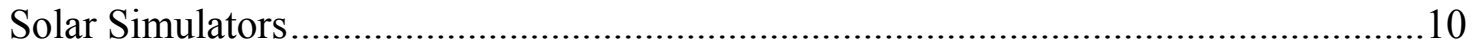

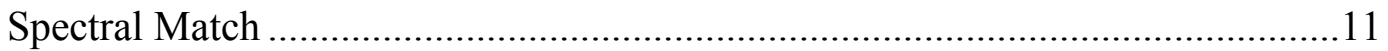

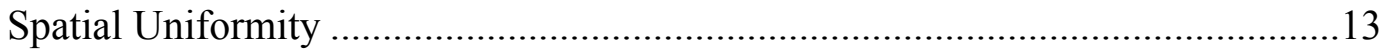

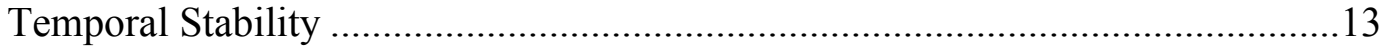

Xenon Lamp Source ………………………….........................................14

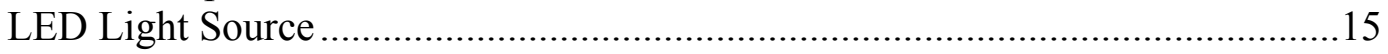

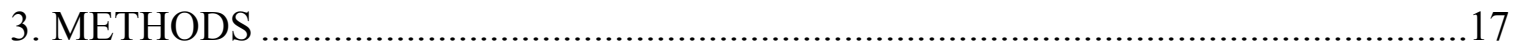

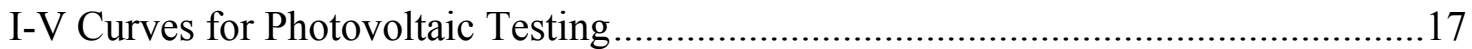

I-V Curve Measurement Setup ............................................................................19

Spectral Response and Quantum Efficiency..............................................................20

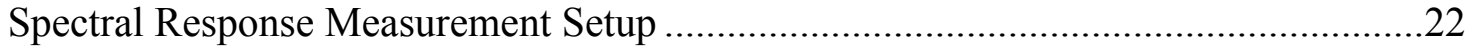

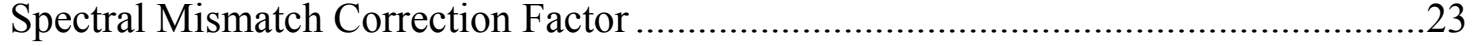

4. TEST RESULTS

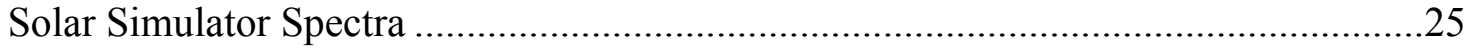

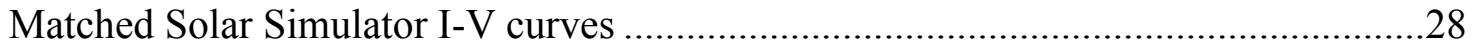

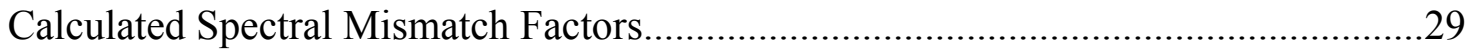

Experimentally Measured Spectral Mismatch .............................................................30

Solar Simulator Temperature Effects......................................................................

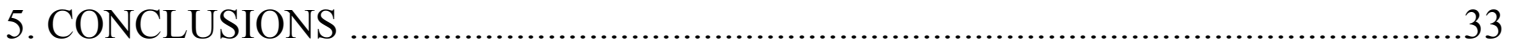

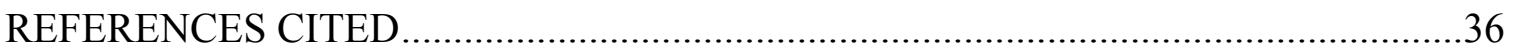

APPENDIX A: IQE200 System Operations Manual.......................................................40 
LIST OF TABLES

Table

Page

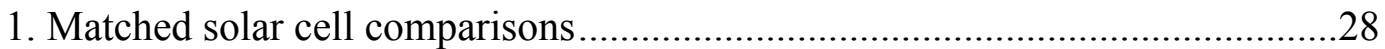




\section{LIST OF FIGURES}

Figure

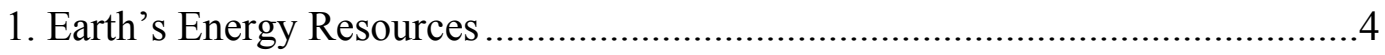

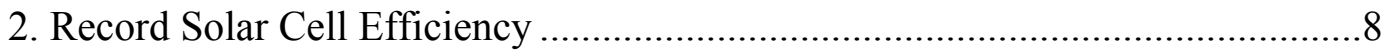

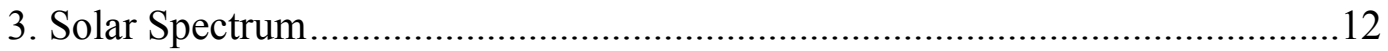

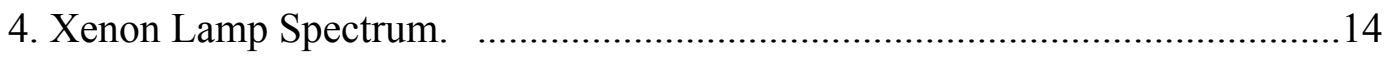

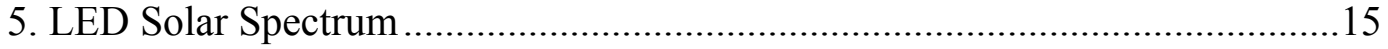

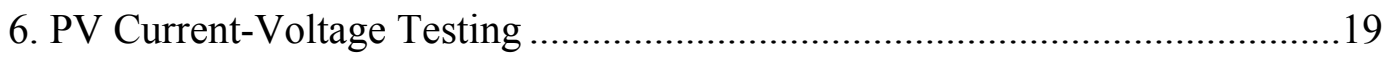

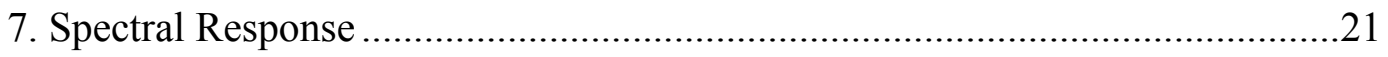

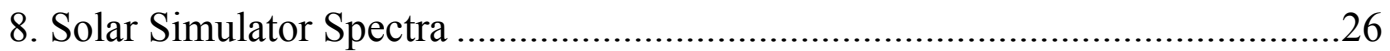

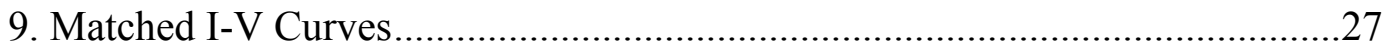

10. Experimentally Determined Spectral Mismatch ........................................... 31

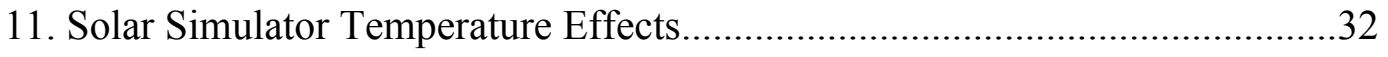




\begin{abstract}
Rapid advances in high intensity light emitting diodes (LEDs) have provided sufficient tools to design LED solar simulators to accurately mimic the sun. LEDs offer numerous advantages over lamp-based technology currently used. However, these advantages have not been harnessed because of limitations in creating a solar simulator with the highest rating (AAA) for spectral match, temporal stability, and light uniformity. Oriel's VeraSol is one of the first LED, triple A solar simulators. The VeraSol-LED is compared to the equally rated Oriel Sol3A-xenon lamp solar simulator by studying the current-voltage (I-V) and spectral response of a variety of solar cells. Both simulators effectively mimic the sun; however, the results demonstrated the LED- based simulator produced a more stable, flexible, and accurate match to AM1.5G than the xenon lamp Sol3A with similar marks in the quality of PV cell response.
\end{abstract}




\section{INTRODUCTION}

A wide variety of light sources, including the natural sun, have been utilized to characterize photovoltaic (PV) systems. A solar simulator is a light source engineered to mimic the sun and used for testing PV cells within a controlled, reproducible environment. Currently, the quality of a solar simulator is graded on the spatial uniformity across a defined illumination area, the temporal stability through the experiment, and the spectral match to the sun from a clearly defined reference spectrum (AM1.5: http://rredc.nrel.gov/solar/spectra/am1.5/). These standards are collected in a series of guidelines put forth by three internationally recognized standards bodies: 1) the IEC (Photovoltaic Devices- Part 9: Solar Simulator Performance Requirements 60904-9), 2) the JIS (Solar Simulators for crystalline solar cells and modules, C 8912), and 3) the ASTM (Standard Specification for Solar Simulation for Terrestrial PV Testing, E927) [1]. A general consensus considers a performance grading (A, B, and C) for spatial uniformity, temporal stability, and spectral match.

Commercially, the xenon arc lamp has dominated the solar simulator light technology of the past 15-20 years. The xenon bulb is very close to an ideal point source of light with a relatively continuous and uniform spectrum across the solar spectrum. However, like many lamp-based simulators, the spectral intensity of the lamp decreases and the irradiance spectrum shifts from blue to red as the lamp ages; the primary change taking place within the first 200 hours of use [2,3].

Recent advancements in LED technology have allowed for a full sun spectral coverage from 400-1100 nm. An LED is a solid-state light source that emits light via 
electroluminescence over a narrow range of the electromagnetic spectrum $(30-50 \mathrm{~nm})$. The parallel combination of unique LEDs can be used to match the AM1.5G spectrum in addition to allowing output control of the light source with a $30-50 \mathrm{~nm}$ resolution $[3,4,5$, and 6]. LEDs seem to be a viable advancement in solar simulator technology because of the added spectral control but also because the LEDs have a longer lifetime, reduced heat, a stable output, fast gating (millisecond), and lower power consumption. The Oriel VeraSol-LED solar simulator is one of the first to achieve an AAA rating for each of the qualifications listed above.

In this manuscript, two AAA rated solar simulators from Newport were compared to characterize any distinguishing features: the xenon lamp-based Oriel-Sol3A and the LED-based Oriel-VeraSol. In the first section, the spectral outputs relative to AM1.5G were considered. In the second section, the I-V response for a series of PV cells was compared: monocrystalline silicon, polycrystalline silicon, thin film amorphous silicon, and thin film copper indium gallium selenide (CIGS). The results demonstrated the LEDbased simulator produced a more stable, flexible, and accurate match to AM1.5G than the xenon lamp Sol3A with similar marks in the quality of the PV cell response. 


\section{BACKGROUND}

\section{The Utility of Solar Energy}

Scott Kelly, an American astronaut aboard the International Space Station, recently described Earth's atmosphere as appearing "very, very fragile" and in specific areas looking "kind of sick". The combustion of fossil fuels not only provides us with a marvel of a world spanning electrical grid, transportation convenience, nearly infinite torque, and seemingly endless warmth, but also with the reality of excess carbon dioxide in the atmosphere and oceans with pollution that hazes our horizons and grips our lungs and minds. Like so much, too much of a good thing is not healthy, and humans have become addicted to fossil fuels [4]. The reality is that this energy consumption is and will be limited by multiple realities: the amount of resources in the earth, climate change, and our ability to conveniently obtain the stored energy cheaply. It seems inevitable that a sustainable future for humans on earth will require an alternative approach to energy.

Energy from the sun has great promise for our future. In an article by Perez et al., 2011, the authors compare the total potential for finite, non-renewable resources with alternative renewable energy resources. Their summary plot is shown in Figure 1. The volume of each sphere on the right side of Figure 1 represents the total recoverable potential of the finite energy resources: coal, uranium, natural gas, and petroleum [5]. The potential sphere on natural gas has grown with the advancements in fracking technology as well as the potential for uranium does not include uranium recoverable from ocean water. The renewables energy spheres (center and left) represent the yearly 


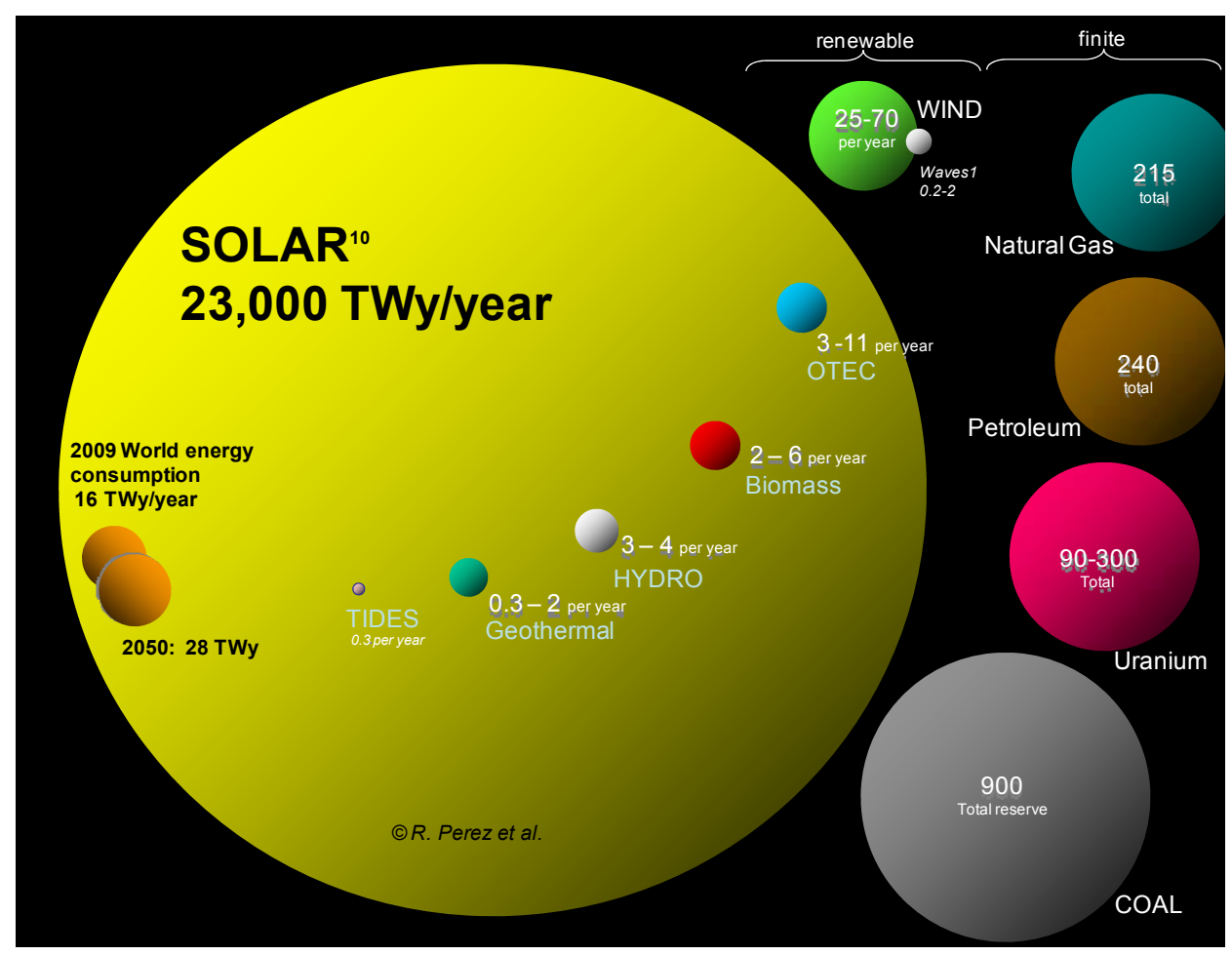

Figure 1: Earth's Energy Resources. Comparing finite and renewable planetary energy reserves (TeraWatt-Years). Total recoverable reserves are shown for finite resources. Yearly potential is shown for the renewables [5].

potential of each renewable resource: wind, biomass, hydroelectric, geothermal, tides, ocean thermal energy conversion (OTEC), and solar. In orange is the worlds annual energy consumption (16 TWy/year) and our projections for 2050 (28 TWy/year). Clearly, solar energy represents the most viable energy resource for our future; stated another way, enough solar energy falls on the earth in 1 hour than what we consume as a civilization in one year [6]. This excess of resource parallels the benefit in that solar energy can also help reduce climate change and pollution, while at the same time maintaining our current technological comforts. Philosophically solar energy makes sense; technologically we still face many challenges. 


\section{Solar Energy Technology}

A variety of solar devices have been used by humans to harvest energy from the

sun. Examples of using the energy from the sun extend back thousands of years and many relevant systems are in high production today; these include applications for drying food, cooking food, heating water for residential houses, heating liquids to drive steam engines, solar cells to generate electricity, solar refrigeration, and solar fuels. Current technology could provide enough energy from the sun to satisfy our current energy demands; however, creative engineering approaches and new scientific research are required to develop feasible storage system to equalize the electrical quality and capacity put forth by our current electrical grid system.

\section{$\underline{\text { Photovoltaic (PV) Solar Cells }}$}

PV panels directly convert solar energy into electrical energy. PV solar cells made from silicon were discovered in the 1950s at Bell labs [7]. Most PV solar cells function on the theory of a p-n junction design in which electron hole pairs are separated by absorbed light and harvested through an external circuit. The conversion efficiency for these devices is about $20 \%$ for current residential rooftop panels, $30 \%$ for high quality space grade PV panels, $45 \%$ for the maximum efficiency tested in a laboratory, and $87 \%$ efficient for a theoretical limit with an infinite number of multilayer solar cells [8].

PV advancements have been carefully tracked by National Renewable Energy Lab (NREL) and are shown in Figure 2. In general, solar cells can be classified into three generations of progress: (1)Wafer-based crystalline silicon, (2) Thin films which include 
amorphous silicon, cadmium telluride, or copper indium gallium selenide, and (3) A new generation that include organic PV cells, Perovskite PV cells, new multiple junction PV cells, and nanomaterials $[9,41]$. Currently, PV research is rapidly advancing and diversifying to improve PV cell performance, material, and decrease cost.

Simultaneously, these advancements require new and more dynamic instrumentation for PV cell characterization.

According to the Fraunhofer 2014 Photovoltaic Report, approximately $90 \%$ of worlds PV market is controlled by crystalline silicon (cSi) and multi-crystalline $\mathrm{Si}(\mathrm{mSi})$ technology [42]. These single $\mathrm{p}-\mathrm{n}$ junction solar cells are limited by a theoretical maximum efficiency of about 33.7\% known as the Shockley-Queisser limit. Currently the highest efficiency achieved has been $25 \%$ [7]. In general, silicon solar cells are made from highly purified silicon; the wafers are thinly cut and doped with $\mathrm{p}$ and $\mathrm{n}$ type atoms, patterned for texture and contacts, coated with an antireflective surface, and sealed in a protective case. Most companies guarantee these solar cells for at least 25 years with the expectation the wiring will degrade before the solar cell itself. The technology is robust yet energy intensive to manufacture.

The idea of thin film solar cells has been around since the 1970s with amorphous silicon (aSi) thin films designed for solar calculators. Thin film PV cells are cheaper to manufacture than crystalline but also slightly less efficient. However, in recent years, a number of copper indium gallium selenide (CIGS) and cadmium telluride (CdTe) thin films solar cells have achieved efficiency conversions above $21 \%$ as shown in Figure 2. This efficiency has passed that of multicrystaline silicon $(\mathrm{mSi})$ solar cells and become 
competitive with moncrystaline solar cells (cSi). In thin film solar cells, the active semi conductive material is layered on a surface with thicknesses that can vary from nanometers to micrometers; this is still much thinner than the crystalline silicon materials which are usually about 200 micrometers thick, a processing limitation caused by the brittleness of crystalline silicon. Although cheaper, one major concern is the use of toxic chemicals to generate these solar cells; a seemingly contrary direction when considering reducing environmental hazards is one of the major benefits of solar cells. This fact itself bolsters silicon solar cells as a more friendly material for our future.

The third generation of solar cells includes a rapid expansion of new materials and approaches to solar cell design. One main goal of these solar cells is to reduce cost, which has resulted in organic photovoltaic (OPV) cells as well as dye-sensitized solar cells (DSSC). OPV use readily available organic molecules to create an organic semiconductor [10]. DSSC use dyes, mimicking photosynthesis, to create the photoexcited charges [11]. Both currently have efficiency values only around $11 \%$, although the cost of production, scalability, nontoxic chemicals, and ability to recycle makes them a potential technology for the future. Perovskite solar cells use a unique chemistry that began out of research on DSSC. These cells are cheap and in the last 7 years they have gone from $4 \%$ to $22 \%$ efficiency demonstrating the robust nature of the design [12]. Also, numerous new materials are being created based on new nanotechnology and chemistry; these materials include graphene, nanorods, quantum dots, and nanotetrapods $[13,14]$. Each of these third generation solar cells is only in the testing phases and has not been significantly applied to large scale testing. 


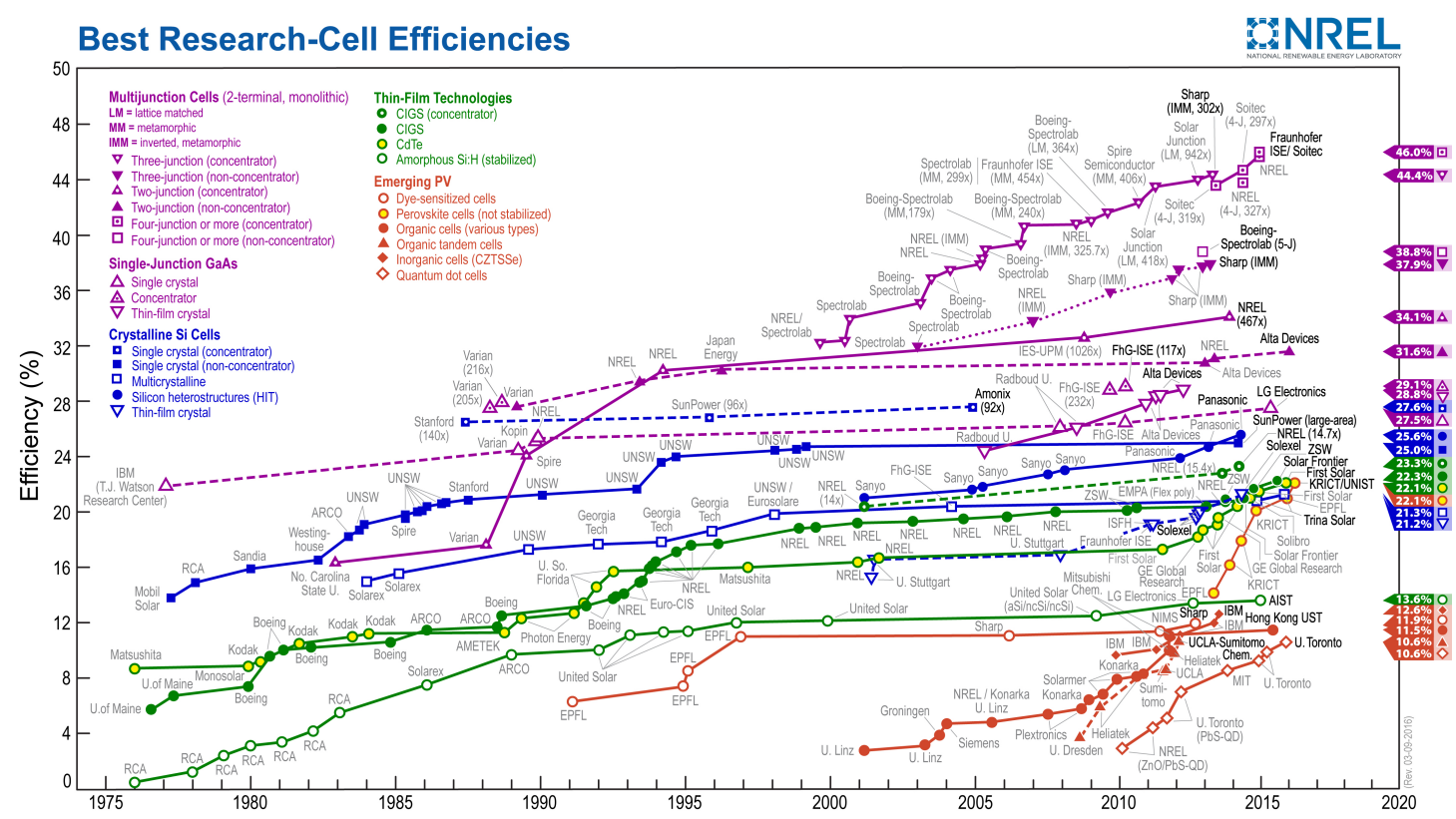

Figure 2: Record Solar Cell Efficiency. NREL solar cell efficiency records since 1976 for research grade solar cells. Purple is for Multijunction Cells; blue is for crystalline Si cells; green is for Thin Film technology; and red is for new emerging solar cells [15].

Solar Thermal Technology

Solar thermal technology converts solar energy into thermal energy [16]. This conversation efficiency for evacuate tubes on rooftops is between $70-90 \%$ efficient and can be used to heat approximately $80 \%$ of hot water demand in a typical Montana residence. Also falling under solar thermal technology is concentrating solar power plants that heat a center liquid/salt and in turn drive steam engines. In the last 7-8 years a number of these grid-sized systems have been implemented around the world. The largest in the world, Ivanpah, is a 392 MW plant in California designed to serve 140,000 homes. There are currently plans for larger scaled plants that range in capacity between 1000-2000 MW in India and China. 


\section{Thermoelectric Technology}

Thermoelectric devices simply covert excess heat into electricity. Thermoelectric devices showcase a potential to limit energy losses by harvesting heat energy using a solid-state device that produces no toxic residuals and is easily scalable. The general principal governing this potential is the Seebeck effect, which states that a temperature difference between two dissimilar conductors/semiconductors produces a voltage difference. Conversely, electricity can be applied to these devices to cause a cooling effect known as the Peltier effect. Thermoelectric devices established in the 1950s had efficiencies around 3\%, and the current efficiency of these devices is only around $8-9 \%$ at best. This limited efficiency has prevented the technology from impacting commercial application, and it is suggest at least a 3 fold increase in this efficiency is needed to compete with other technologies currently used for similar purposes [17]. Recently, a thermoelectric nanomaterial based on telluride was discovered that has the theoretical promise of $15-20 \%$ efficiencies [18].

Specific thermoelectric materials can be applied to different types of solar applications over select temperature ranges $[19,20,21]$. This is an advantage of photovoltaic panels that have decreased efficiency with increased temperature. From 30200 degrees, the most common thermoelectric material, bismuth telluride alloys with a ZT values between $0.4-0.7$, can be used for evacuated tubes and flat plate solar thermal panels. From 200-500 degrees C PbTe/PbSe alloys, skuterudites and half-heuslers can be utilized for parabolic trough and linear Fresnel collectors. Finally, at extreme temperature applications (solar towers and large parabolic dishes), silicon germanium alloys can be 
used [22].

\section{$\underline{\text { Solar Fuels }}$}

One of the holly grails of solar conversion is to create solar fuels. In early 2016, a coalition headed by Bill Gates and a number of leading entrepreneurs have designated carbon free energy as a grand challenge for humans in a new "Breakthrough Energy Coalition"; solar fuels is one source they highlighted as an attainable and important goal for our future. The idea is to use a solid-state device made from cheap materials that can harvests sunlight and directly produces fuels. This would side step the need for largely deployed energy storage required with current PV technology [23]. This process has also been termed artificial photosynthesis. Ideally devices would generate hydrogen gas from water which when combusted would return the separated water. Also, there is much interest in producing hydrocarbons like gasoline that could be directly fused into our current economy. Currently, there is no device that can complete the full conversion, but sensitizers and catalysts have been created that can perform part of the reaction path [24]. In parallel, an "artificial leaf" has been created that uses PV cells combined with these catalysts to split water and make oxygen and hydrogen gas [25].

\section{$\underline{\text { Solar Simulators }}$}

Each of these solar technologies and fields of research requires a device, such as a solar simulator, for reproducible testing within a laboratory. A solar simulator is a laboratory instrument used to mimic the sun; it is an artificial light source. Since solar cells were only really created in the 1950 at Bell labs, the history of solar simulators has 
only established a literature base over the past 40 years. The literature has culminated into in a series of guidelines put forth by three internationally recognized standards bodies: 1) the IEC (Photovoltaic Devices- Part 9: Solar Simulator Performance Requirements 60904-9), 2) the JIS (Solar Simulators for crystalline solar cells and modules, C 8912), and 3) the ASTM (Standard Specification for Solar Simulation for Terrestrial PV Testing, E927) [1]. A general consensus considers a performance grading (A, B, and C) for spatial uniformity, temporal stability, and spectral match.

\section{$\underline{\text { Spectral Match }}$}

The spectral match grades how well a solar simulator mimics the suns output spectrum. The sun spectrum varies depending on where one is at any time on earth; however a couple standard spectra have been established to control this variability when testing PV devices. Three established spectra standards are accepted when matching the irradiance spectrum of the sun with solar simulators: AM0, AM1.5D, and AM1.5G. Both the xenon lamp Sol3A and the LED-VeraSol used in this study qualify for a class A rating between $400 \mathrm{~nm}$ and $1100 \mathrm{~nm}$ on AM1.5G.

Air mass (AM) is the path length that light travels through the atmosphere normalized to the shortest possible path (AM1). Any air mass can be calculated knowing the zenith angle $(\theta)$ by using the following equation.

$$
\operatorname{Air} \text { Mass }=\frac{1}{\cos \theta}
$$

The zenith angle $(\theta)$ is the angle relative to the shortest possible path of the sunlight vertically overhead (AM1). AM0 is the irradiance outside of the Earth's atmosphere 
(zero atmospheres), and AM1.5 corresponds to a standard at a zenith angle of $\sim 48.5^{\circ}$;

AM1.5 also corresponds to the common one sun irradiance of $1000 \mathrm{~W} / \mathrm{m}^{2}$ used to standardize PV cell testing. AM1.5D indicates the direct component spectrum of the irradiance that strikes the Earth's surface, and AM1.5G (global), the most commonly represented spectrum, accounts for both the direct and diffuse radiation striking the Earth's surface.

AM0 is represented by the yellow curve in Figure 3. The black line models the expected black body radiation at $5250^{\circ} \mathrm{C}$. This type of spectrum is needed to test space grade solar cells. The AM0 spectrum begins to rise at about $250 \mathrm{~nm}$ and extends beyond

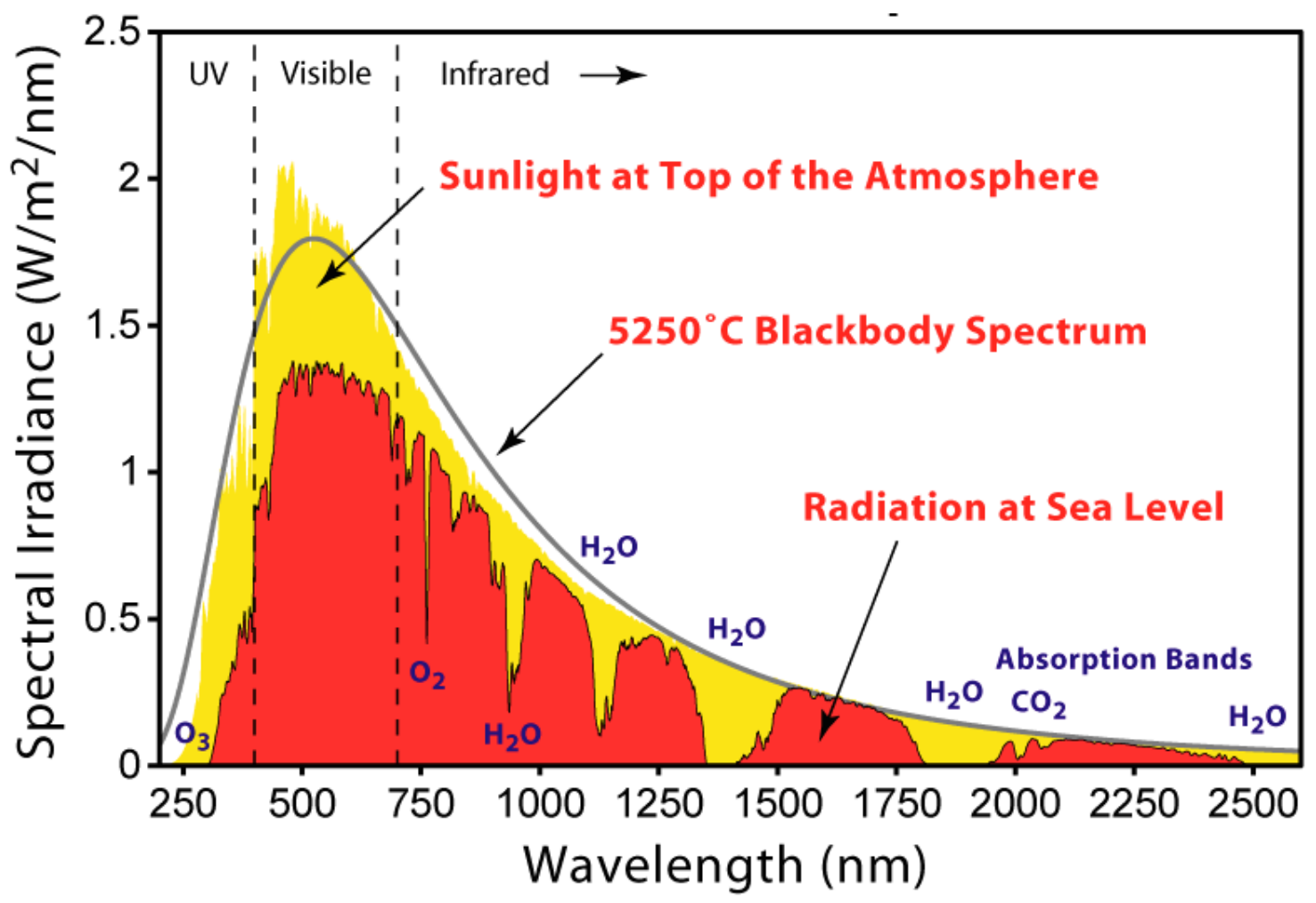

Figure 3: Solar Spectrum. The solar irradiance spectrum at the top of the earths atmosphere (AM0_yellow), at sea level (AM1.5d_red), and with the model for a blackbody radiation source at $5250^{\circ} \mathrm{C}[26]$. 
$2500 \mathrm{~nm}$. The peak of the solar spectrum is over the visible region, which makes sense that humans and other organism would develop light detection for this spectral region. As sunlight travels through our atmosphere energy is absorbed by different molecules such as ozone, water, oxygen and carbon dioxide. The spectrum in red represents the AM1.5D; this is the spectrum measured at the earth surface; the AM1.5g has slightly more energy because of the additional diffuse radiation that is included.

\section{Spatial Uniformity}

The second criterion for grading solar simulators is the spatial uniformity or irradiance inhomogeneity; this is the consistency of light over a selected test region. For a class $\mathrm{A}$ rating there needs to be less than $\mathrm{a}+/-2 \%$ variation over the test region. This criterion has the greatest difference between the three recognized standards. The IEC is the most difficult because it divides the entire test region into 64 equally sized squares and measures each division. The ASTM 927-05 method recommends 36 equally spaced samples which has the potential to cover half the region of the IEC, and the JIS method establishes a lower sample grid that covers both circular and square test regions [1]. The criteria of $+/-2 \%$ is the same in all three standards, but the methods of establishing the sampling obscures the true class rating of solar simulators.

\section{Temporal Stability}

The third criterion is the temporal stability of the instrument; this is the ability to maintain one sun output over both long term and short-term experiments. Often times a solar cell will be exposed to light for as brief as possible through some type of gating 
mechanism, enough to sweep and I-V curve from the solar cell yet not heat the sample. For a class A-rating, the solar simulator must have only a $0.5 \%$ variability over long term experiments and a $2 \%$ variability over short term experiments.

\section{Xenon Lamp Technology}

Conventional solar simulators have long relied on xenon arc lamp technology to match the solar spectrum. Although other lamps and filaments are suitable, xenon arc lamps have a color temperature almost identical to the sun at about $5400 \mathrm{~K}$ [27]. The result is an excellent spectral coverage in the ultra violet and visible bands with emission lines in the infrared that can be filtered to closely match the sun spectrum (Figure 4A). Xenon arc lamps also behave as an almost ideal point source, which is useful to produce a collimated high intensity light beam [27]. However, the xenon bulb has drawbacks: 1) the xenon lamp consists of a pressurized gas that has the potential to be hazardous, 2) aging of the lamp alters the spectral irradiance enhancing the IR contribution and reducing the UV (Figure 4B), 3) power supply instabilities can significantly effect amplitude stability in the output, 4) the filters create a permanent mismatch that cannot be adjusted, and 5) the bulbs have a short life and are relatively expensive [3, 28, 29]. 

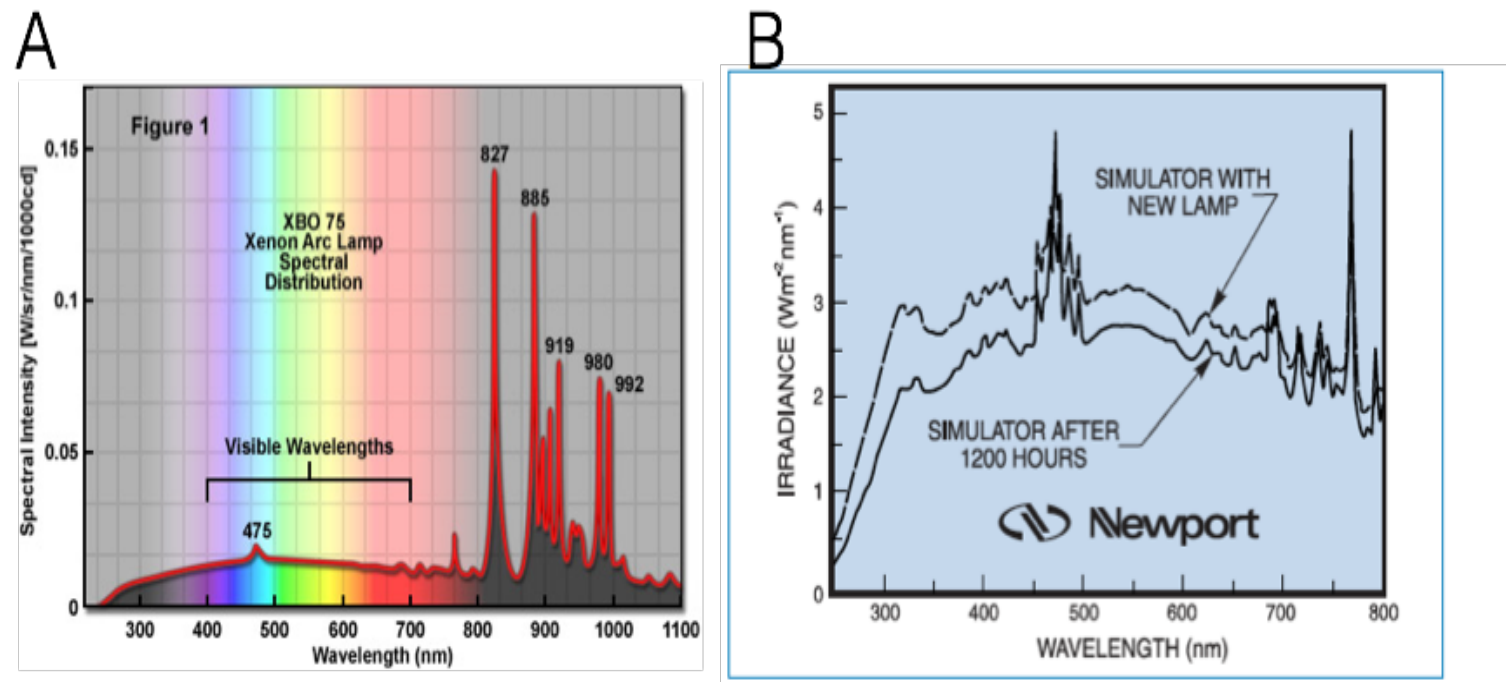

Figure 4: Xenon Lamp Spectrum. A. Xenon arc lamp spectrum highlighting the continuous spectrum through the visible and UV regions much like the solar spectrum. Also shown is the complex line spectrum between 700-1000 nm [30]. B. The spectral irradiance for a xenon lamp before and after 1200 hours of operation in a Newport solar simulator [31].

\section{LED Technology}

With evolving solar cells, experiments will require more dynamic functionality of a solar simulator. LED technology may significantly improve the capability of a solar simulator. LEDs are solid-state devices that don't require the maintenance or have hazards related to a pressurized lamp. Figure 5 shows the 20 or so LEDs used for the VeraSol solar simulator and the summed irradiance output. Each LED has a Gaussian shape emission profile. The parallel combination of unique LEDs can be used to match the AM1.5G spectrum in addition to allowing output control of the light source with a 30$50 \mathrm{~nm}$ resolution $[27,28,32,37,38,39,40]$.

Advancing the simulator light source to LEDs in the future may offer numerous advantages. 1) With the rapid expansion of high intensity LEDs, considerable improvements in unique LED that cover the electromagnetic spectrum and performance 
are expected in the not so distant future. 2) The LED is a solid-state device that produces less variable output. This stability variation compared to the xenon lamp can be clearly differentiated directly from the variation in the solar cell output current. 3) The LEDs have life expectancies of 50,000-100,000 hours. In comparison, the xenon bulb is expected to be replaced after about $\sim 1000$ hours of operation. This should reduce the maintenance cost of a solar simulator as well as alleviate the aging problems expected with the xenon bulb at $\sim 200$ hours $[3,28]$. 4) LEDs consume less energy and pack much smaller than conventional lamp based housings. These benefits, however, do not come without a few issues that need engineering solutions. One issue is thermal stability that is detrimental to LED efficiency, lifetime, and output energy; currently it seems multiple groups have designed solutions to this problem (Oriel VeraSol-LED and [32]). A second issue is that current LED intensities are too low for concentrating solar simulator, limiting the technology to only traditional solar simulators at present. 


\section{METHODS}

\section{I-V Curves for Photovoltaic Testing}

Photovoltaic cells are large PN junctions, which generate electricity when the absorption of light provides energy to separate electron hole pairs within a cell. In the absence of light, a PV responds like a diode. A voltage sweep of a diode with a source meter produces a current/voltage characteristic (I-V) in which the current is exponentially related to an applied voltage,

$$
\mathrm{I}=\mathrm{I}_{0}\left(\mathrm{e}^{\frac{\mathrm{qV}}{\mathrm{kT}}-1}\right)
$$

where $I_{0}$ is the saturation current [A] of the diode, $q$ is the charge of an electron [C], $k$ is the Boltzmann constant $\left[\mathrm{m}^{2} \mathrm{~kg} / \mathrm{s}^{2} \mathrm{~K}\right], T$ is the temperature [K], and $V$ is the applied voltage $[\mathrm{V}]$. When light is applied to the PV cell, the I-V curve is a superposition of the I-V in the dark (diode current) with the light-generated current (photovoltaic current $\left(\mathrm{I}_{\mathrm{L}}\right)$ ); light causes a shift of the I-V curve down the y-axis into the fourth quadrant, and the equation becomes

$$
I=I_{0}\left(e^{\frac{q V}{k T}}-1\right)-I_{L} .
$$

Plotting the I-V curve in the first quadrant (see Figure 6B), which is useful for presentation of the power generated curve $(\mathrm{P}=\mathrm{VI})$, is achieved by simply subtracting the diode current from the photoelectric current $\left(\mathrm{I}_{\mathrm{L}}\right)$ 


$$
\mathrm{I}=\mathrm{I}_{\mathrm{L}}-\mathrm{I}_{0}\left(\mathrm{e}^{\left.\frac{\mathrm{qV}}{\mathrm{kT}}-1\right)}\right.
$$

Figure 6A represents a simple, equivalent circuit model for a PV cell, which includes the ideal model described above, along with additional series and parallel shunt resistance.

The shunt resistance $\left(\mathrm{R}_{\text {shunt }}[\mathrm{ohms}]\right)$ is related to manufacturing defects which can increase the rate of recombination or junction shorting, both of which reduce optimal current flow through the solar cell. The Series Resistance $\left(\mathrm{R}_{\text {series }}[\mathrm{ohms}]\right)$ is related to the ability of current to move through layers of the solar cell and is thus dominated by resistances associated with the semiconductor layers, metal/silicon contacts, and metal on the front and rear surfaces. The following equation adds both the series and shunt resistances into the diode equation above.

$$
I=I_{L}-I_{0}\left(e^{\frac{q\left(V+I R_{\text {series }}\right)}{k T}}-1\right)-\frac{V}{R_{\text {shunt }}}
$$

Although more exact models can better describe the PV cell's I-V characteristic, this model incorporates the main components necessary for an initial characterization. Useful information about internal resistances and operating parameters can be attained from both dark sweep and light stimulated I-V curves.

The PV cell efficiency ( $\eta$, which is the ratio of electrical power output of a PV cell to the incident optical power (Pout/Pin), is the most widely accepted and fundamental value used to characterize a PV cell. It can be calculated from four parameters, which are determined from a single light stimulated I-V curve: the open circuit voltage $\left(\mathrm{V}_{\mathrm{oc}}\right)$, the short circuit current $\left(\mathrm{I}_{\mathrm{sc}}\right)$, the voltage at maximum power $\left(\mathrm{V}_{\mathrm{mp}}\right)$, and the current at 

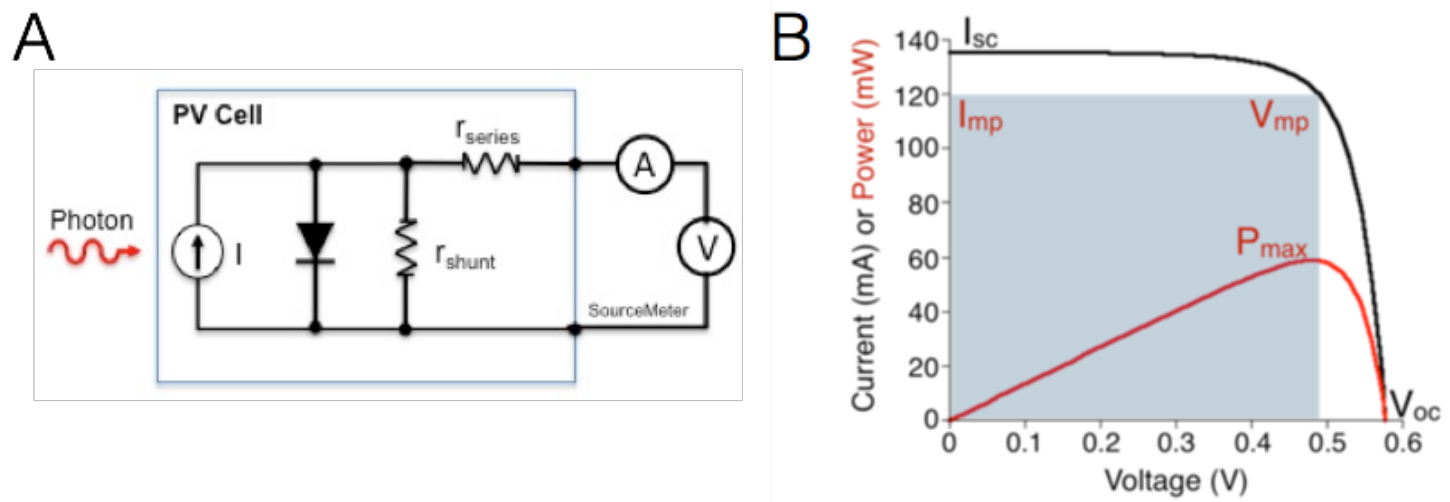

Figure 6: PV Current-Voltage Testing. A. A simple diode circuit model describing a PV cell connected to a source meter for PVIV testing. B. A sample I-V curve taken from a monocrystalline silicon PV cell $\left(4 \mathrm{~cm}^{2}\right)$ using the Oriel PVIV Kit.

maximum power $\left(\mathrm{I}_{\mathrm{mp}}\right)$ (shown graphically, Figure $6 \mathrm{~B}$ ). $\mathrm{V}_{\mathrm{oc}}$ and $\mathrm{I}_{\mathrm{sc}}$ are the maximum voltage and current achieved by a solar cell and are defined by the intercepts on the $\mathrm{x}$ and y-axis, respectively. At both of these operating points the power produced by the solar cell is zero (Figure $6 \mathrm{~B})$. The current $\left(\mathrm{I}_{\mathrm{mp}}\right)$ and voltage $\left(\mathrm{V}_{\mathrm{mp}}\right)$ at the maximum power point define the characteristic resistance $\left(\mathrm{R}_{\mathrm{ch}}\right)$ and the optimal operating conditions for a solar cell; this represents the maximum power possibly generated by a PV cell. The fill factor (FF), known as "squareness" of an I-V curve, is the ratio of the rectangular area $\left(\mathrm{V}_{\mathrm{mp}} \mathrm{X}\right.$ $I_{m p}$ ) from the maximum power point to the rectangular area produced by $V_{\text {oc }} \times I_{s c}$. Finally, the efficiency is the ratio of the maximum power output to the input power produced by the light source, scaled to the area of the cell under test.

\section{$\underline{\text { I-V Measurement Setup }}$}

The standard test conditions (STC) for characterizing the efficiency of a PV cell require that measurements are made at a spectral match of $\mathrm{AM} 1.5 \mathrm{G}$, at an irradiance of 1 
sun, and at a temperature of $25{ }^{\circ} \mathrm{C}$. The spectral match, uniformity of irradiance, and temporal stability of the irradiance are used to grade the performance of commercial solar simulators. The solar simulator designation AAA gives the highest rating of A to all three: spectral match, uniformity and stability.

In this application, the Xenon lamp-based Oriel Sol3A Class AAA and the LEDbased VeraSol Class AAA were used to simulate the sun. Both devices are optimized to emit light at the required one sun, and both allow for a range of intensities from 0.1-1.0 suns. Additionally, samples are maintained at $25{ }^{\circ} \mathrm{C} \pm 1{ }^{\circ} \mathrm{C}$. It can be useful to scan the test cell from $V_{o c}$ to $I_{s c}$ due to sensitivity of $V_{o c}$ to temperature.

An Oriel PVIV Kit was used to generate the following I-V curves. A Keithley 2420 SourceMeter is included with the kit to source the voltage and measure the resulting current. Four-wire (Kelvin) connections are recommended for PV cell I-V curves thus accounting for any resistance associated with connecting leads to the PV cell. Kelvin probes from Accuprobe allow precise and isolated contact of the two inputs to a small PV cell bus bar. In general, the cables throughout the system should be as short as possible to minimize resistive or inductive artifacts.

\section{Spectral Response and Quantum Efficiency}

Measuring the spectral response (SR) provides information about the recombination of electron-hole pairs, diffusion mechanisms, the band gap, and the reflectance/transmittance of light [33]. The SR is the amount of current generated in the solar cell at short circuit $\left(\mathrm{I}_{\mathrm{sc}}\right)$ relative to the incident power at each wavelength and is 


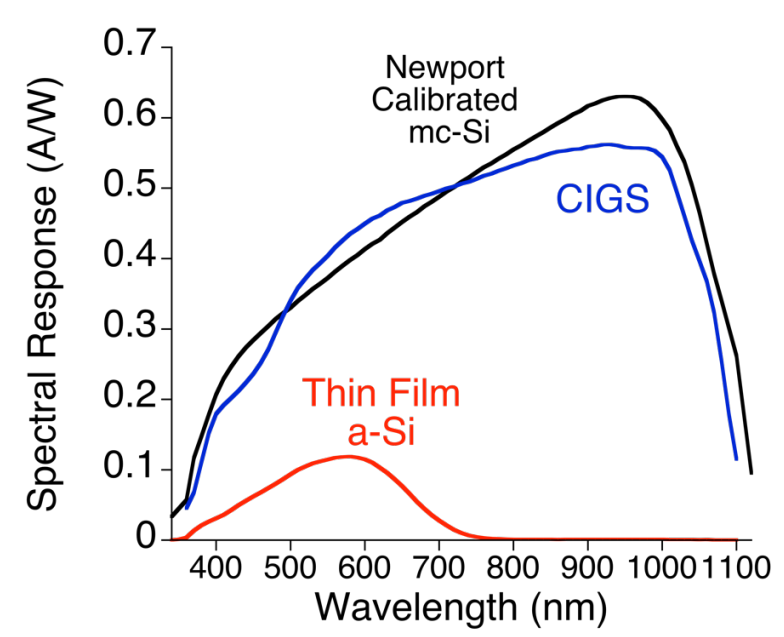

Figure 7: Spectral Response. The spectral response for solar cells taken on an IQE200. Measurements were taken between $360 \mathrm{~nm}$ and $1100 \mathrm{~nm}$. The calibrated crystalline silicon cell is shown in black, the CIGS thin film is shown in blue, and the amorphous silicon thin film is shown in red.

measured in units of A/W. Figure 7 illustrates the spectral response from an IQE200 (Newport) for PV cells tested in this manuscript; the crystalline PV cell was not presented because of its similarity to the calibrated Newport calibrated crystalline PV cell.

The SR can be converted to a quantum efficiency $(\mathrm{QE})$ curve that intuitively relates the number of electrons generated in a PV device to the number of incident photons.

$$
E Q E=\frac{h c}{q \lambda} S R=\frac{1239.8}{\lambda} \cdot S R
$$

The scaling factor for the conversion, $\frac{h c}{q}=1239.8$, arrives from Planck's constant $(\mathrm{h}$ $\left.\left[\mathrm{m}^{2} \mathrm{~kg} / \mathrm{s}\right]\right)$, the speed of light (c $\left.[\mathrm{m} / \mathrm{s}]\right)$, and the charge of an electron (q [C]). An external quantum efficiency (EQE [electrons/photon]) does not account for optical losses from the reflectance or transmittance of light; if these losses are measured, an internal quantum 
efficiency (IQE) curve can be generated that determines the efficiency for only light that reaches the solar cell.

The SR can be related to an I-V curve through the $\mathrm{I}_{\mathrm{sc}}$ for a selected reference or simulator illumination spectrum. At each wavelength the spectral response $\left(S_{t}(\lambda)[\mathrm{A} / \mathrm{W}]\right)$ of a test cell is multiplied by spectral irradiance of the simulator $\left(\mathrm{E}_{\mathrm{sim}}\right.$ $\left.\left[\mathrm{W} / \mathrm{m}^{2} \mathrm{~nm}\right]\right)$ or selected reference spectrum $\mathrm{E}_{\mathrm{AM} 1.5 \mathrm{G}}$; the integral of this product with respect to wavelength produces the expected short circuit current in amps

$$
I_{s c}=A \int_{\lambda_{1}}^{\lambda_{2}} S_{t}(\lambda)_{c e l l} * E_{\text {sim }}(\lambda) d \lambda
$$

where $\mathrm{A}$ is the area of the solar cell.

\section{$\underline{\text { Spectral Response Measurements }}$}

The spectral response for each solar cell was determined with an IQE200 (Newport). PV cells were short circuited, and a QTH lamp was used to excite the sample. The lamp was turned on for at least 30 minutes prior to testing. The system did not have ability to determine the diffuse component of the scattered light and so no IQE was reported. Samples were measured between 360nm and $1100 \mathrm{~nm}$ (the limit of our

silicon detectors). The SR was converted to a quantum efficiency (QE) curve that more intuitively relates the number of electrons generated in a PV device to the number of incident photons. 


\section{Spectral Mismatch Correction}

Since no solar simulator perfectly matches the sun, a spectral mismatch factor (M) is needed to scale the I-V response from the simulator to the desired reference spectrum (e.g. AM1.5G). The spectral mismatch factor has been reviewed previously at Newport in Application Note 51 [34] and is summarized here. The spectral mismatch factor (M) is the ratio of the short circuit current for the reference cell under both AM1.5G ( $\left.\mathrm{I}_{\mathrm{ref}(\mathrm{AM} 1.5 \mathrm{G})}\right)$ and solar simulator excitation $\left(\mathrm{I}_{\mathrm{ref}(\mathrm{VeraSol})}\right)$ multiplied by the short circuit current for the test cell at both AM.1.5G ( $\left.\mathrm{I}_{\mathrm{PV} \text { cell(AM1.5G) }}\right)$ and solar simulator ( $\left.\mathrm{I}_{\mathrm{PV} \text { cell(VeraSol }}\right)$.

$$
M=\frac{I_{P V \operatorname{cell}(\text { VeraSol })} \times I_{\text {ref }(\text { AM } 1.5 G)}}{I_{P V \operatorname{cell}(A M 1.5 G)} \times I_{\text {ref }(\text { VeraSol })}}
$$

This mismatch factor can be calculated by individually determining the short circuit current for each component considering Equation 6.

$$
M=\frac{\int_{\lambda_{1}}^{\lambda_{2}} S_{P V \text { cell }} * E_{\text {VeraSol }} \times \int_{\lambda_{1}}^{\lambda_{2}} S_{\text {ref }} * E_{A M 1.5 G}}{\int_{\lambda_{1}}^{\lambda_{2}} S_{P V \text { cell }} * E_{A M 1.5 G} \times \int_{\lambda_{1}}^{\lambda_{2}} S_{\text {ref }} * E_{\text {VeraSol }}}
$$

It has become standard practice to use a calibrated AM1.5G PV cell (e.g. Oriel Part Number: $91150 \mathrm{~V})$ to adjust the simulator to an equivalent one sun short circuit current as would be measured at AM1.5G. This simplifies the calculation for the mismatch factor.

$$
M=\frac{\int_{\lambda_{1}}^{\lambda_{2}} S_{P V \text { cell }} * E_{\text {Verasol }}}{\int_{\lambda_{1}}^{\lambda_{2}} S_{P V \text { cell }} * E_{A M 1.5 G}}
$$


This relationship has traditionally been used to account for the fundamental difference in light sources from a desired reference spectrum. The calculation is demonstrated below for a thin film module measured with the two solar simulators compared in this study, the Sol3A and the VeraSol, which are adjusted to the reference spectrum AM1.5G. 


\section{TEST RESULTS}

\section{$\underline{\text { Solar Simulator Spectra }}$}

Solar simulators are designed to mimic incident light from the sun. Three established spectra standards are accepted when matching the irradiance spectrum of the sun with solar simulators: AM0, AM1.5D, and AM1.5G: AM0 is the irradiance outside of the Earth's atmosphere (zero atmosphere), AM1.5D is the direct component of the irradiance that strikes the Earth's surface, and AM1.5G (global), the most commonly represented spectrum, accounts for both the direct and diffuse radiation striking the Earth's surface.

Presented in Figure 8 is the VeraSol-LED and Sol3A-xenon lamp spectra overlaid with the desired match to AM1.5G. The standard to a class $\underline{A}$ rating in spectral match requires a +/- 25\% match to AM1.5G over each $100 \mathrm{~nm}$ section of the spectrum; both simulators have a class A rating. An alternative perspective of the total irradiance match can be made by integrating to obtain the area of each curve. From 400-1100 nm, the VeraSol-LED $\left(760 \mathrm{~W} / \mathrm{m}^{2}\right)$ provides a closer spectral match to the AM1.5G $\left(756 \mathrm{~W} / \mathrm{m}^{2}\right)$

than the lamp-based Sol3A $\left(818 \mathrm{~W} / \mathrm{m}^{2}\right)$. Using the VeraSol-LED, this spectral match can be further adjusted by altering individual LEDs to compare more accurately to other desired spectra comparisons or isolate specific spectral regions of interest. 

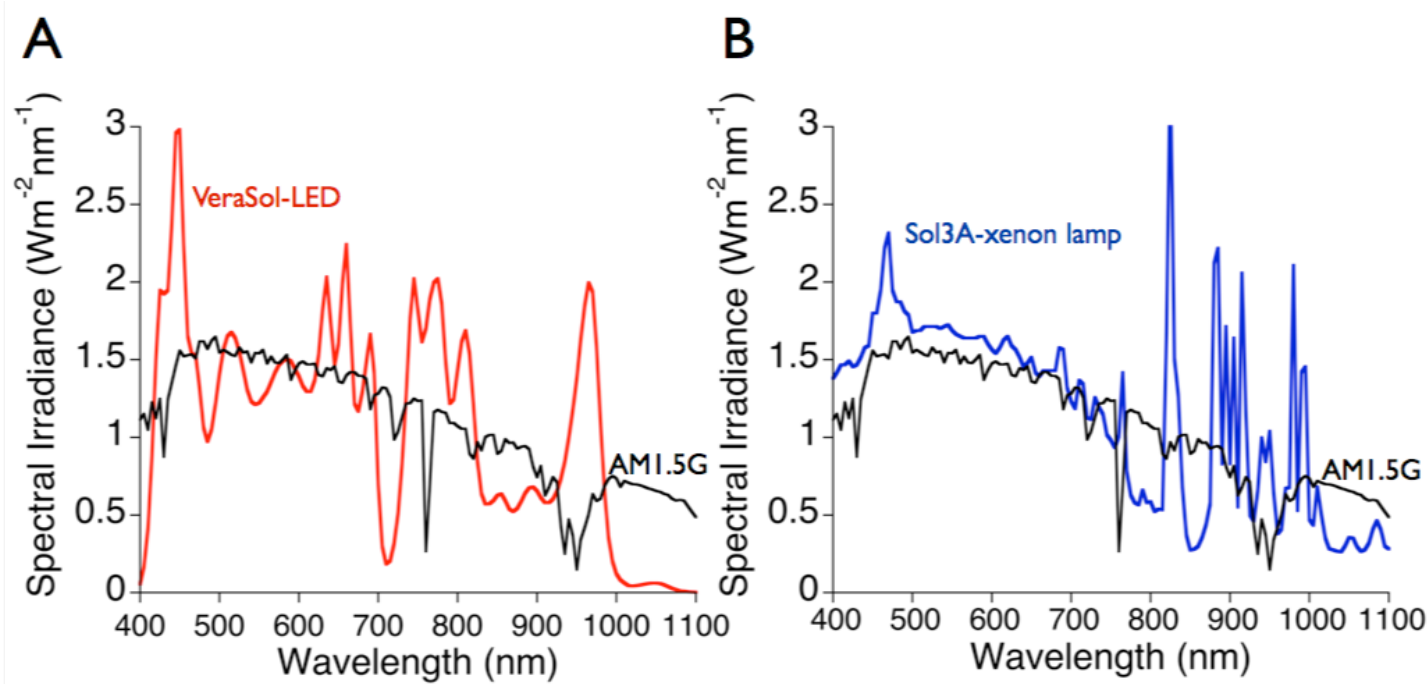

Figure 8: Spectral match of the VeraSol-LED (A-red) and Sol3A-xenon lamp (Bblue) simulator to the AM1.5G spectrum (black), which is seen in both figures.

The majority of solar simulators currently sold rely on the xenon arc lamp optically filtered to match the AM1.5G spectrum. For the Sol3A, the xenon lamp produces more photons than the AM1.5G spectrum especially between $400-700 \mathrm{~nm}$, and this can be seen in Figure 8B. This region overlaps with the majority of energy produced by the sun (centered at $\sim 500 \mathrm{~nm}$ ) and thus causes a significant spectral mismatch.

LED-based light sources offer an alternative engineering approach to solar simulators. Each LED represents a Gaussian illumination source centered on the peak of a LED numerical identifier; this allows multiple options to slightly tweak the existing spectral response by varying the current driving each LED with a rough resolution of 30$50 \mathrm{~nm}$. A narrow dip in the spectrum beyond $700 \mathrm{~nm}$ is a result of an optical filtering that is currently unavoidable in the VeraSol-LED design (Figure 8A); however, these photons are compensated by increasing LED photons to the left and right of the $700 \mathrm{~nm}$ 

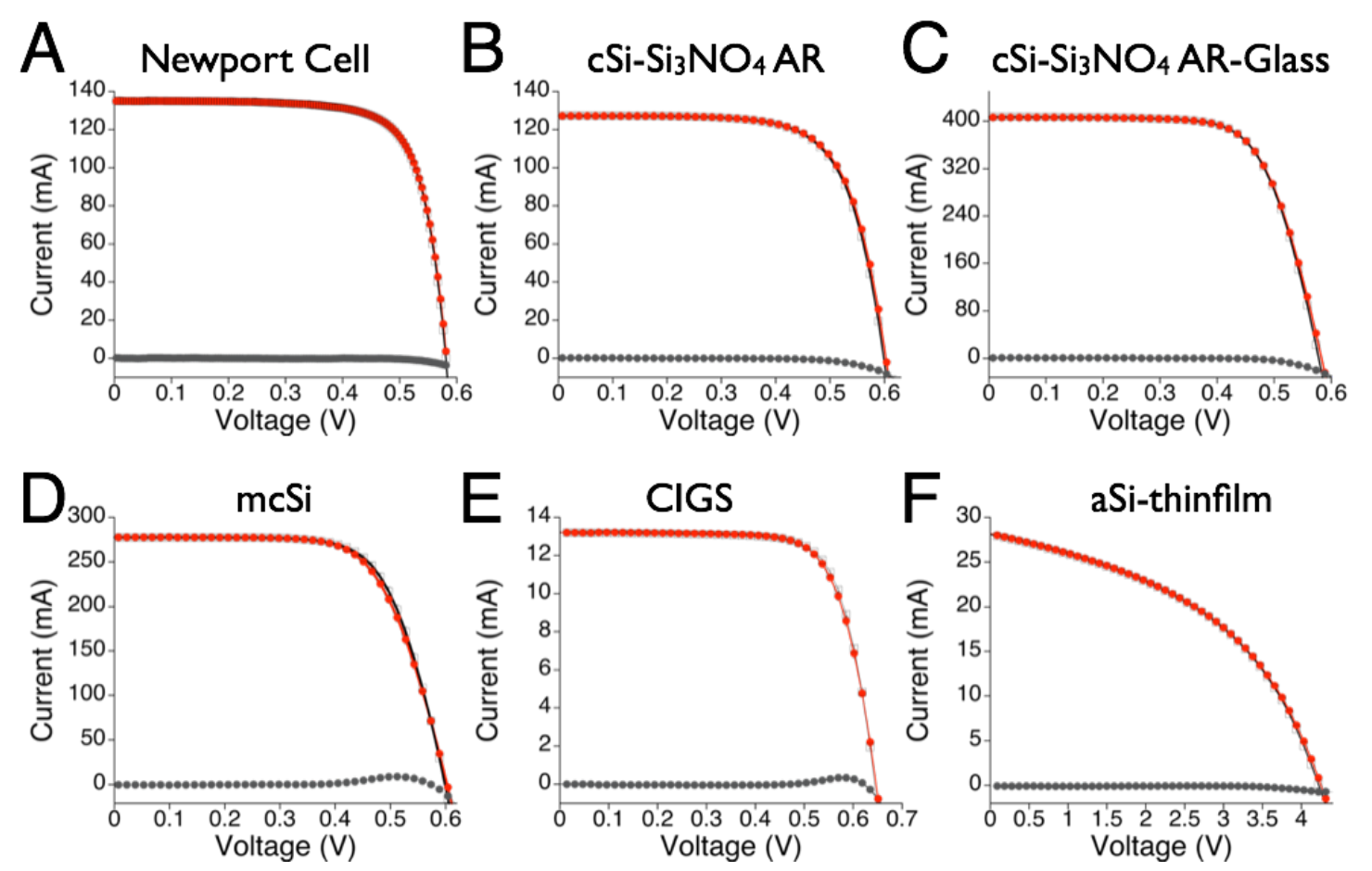

Figure 9: Short circuit current matched IV curves for different PV cells. The Sol3A lamp simulator response (black) was set to one sun using the calibrated Newport cell, and the short circuit current was matched with the VeraSol LED simulator (red). The difference between the two simulator curves is shown in grey as the residual. A. Calibrated Newport monocrystalline PV cell, B. monocrystalline PV cell with silicon nitride antireflective coating (AR), monocrystalline PV cell with silicon nitride AR coating under a glass cover, D. mutlicrystalline silicon PV cell, E. Copper indium gallium selenide (CIGS) thin film solar cell, and F. Amorphous silicon thin film PV cell

dip in the spectrum. The underrepresentation of light above $1000 \mathrm{~nm}$ is simply a limitation from LEDs currently unavailable for this spectral region.

It is essential to realize that simply dimming or removing an LED does not only alter the numerical identifier wavelength but wavelengths to both sides of the numerically identified LED wavelength. Removing individual wavelengths can be used to estimate the bandgap of a PV cell, but often because energy from multiple LEDs contribute to 
each wavelength, it is difficult to estimate a true SR response that an IQE or EQE instrument achieves with momochromaters and slits.

\section{Matched Solar Simulator Induced I-V curves}

A calibrated, monocrystalline silicon PV cell (Newport Part Number: 91150V) was tested by matching the one sun $\mathrm{I}_{\mathrm{sc}}(135 \mathrm{~mA})$ for both light sources (Figure 9A). This $\mathrm{I}_{\mathrm{sc}}$ corresponded to the number of photons required for one sun illumination at AM1.5G for this calibrated PV cell. No statistical difference was apparent for efficiency, open circuit voltage $\left(\mathrm{V}_{\mathrm{oc}}\right)$, or short circuit current $\left(\mathrm{I}_{\mathrm{sc}}\right)$. Comparable results were also obtained for each of the solar cells compared in this study when the $\mathrm{I}_{\mathrm{sc}}$ were matched at both simulators. In general the gross properties of the I-V curve response produced from the two simulators were very similar under matched short circuit current conditions.

\begin{tabular}{|c|c|c|c|c|}
\hline & Simulator & Efficiency (\%) & $V_{o c}(V)$ & $I_{s c}(m A)$ \\
\hline $\begin{array}{l}\text { Newport Calibrated } \\
\text { Cell }\end{array}$ & $\begin{array}{l}\text { VeraSol } \\
\text { Sol3A }\end{array}$ & $\begin{array}{l}14.57+/-0.01 \\
14.67+/-0.04\end{array}$ & $\begin{array}{l}0.5818+/-0.0001 \\
0.5810+/-0.0004\end{array}$ & $\begin{array}{l}135.00+/-0.04 \\
135.00+/-0.13\end{array}$ \\
\hline $\begin{array}{l}\text { cSi-Silicon Nitride AR } \\
\text { Coating }\end{array}$ & $\begin{array}{l}\text { VeraSol } \\
\text { Sol3A }\end{array}$ & $\begin{array}{l}15.26+/-0.004 \\
15.20+/-0.084\end{array}$ & $\begin{array}{l}0.613+/-0.0004 \\
0.608+/-0.0005\end{array}$ & $\begin{array}{l}180.05+/-0.10 \\
180.02+/-0.05\end{array}$ \\
\hline $\begin{array}{l}\text { cSI-Glass / Silicon } \\
\text { Nitride AR }\end{array}$ & $\begin{array}{l}\text { VeraSol } \\
\text { Sol3A }\end{array}$ & $\begin{array}{l}12.54+/-0.09 \\
12.53+/-0.38\end{array}$ & $\begin{array}{l}0.583+/-0.0001 \\
0.578+/-0.0005\end{array}$ & $\begin{array}{l}406.38+/-0.12 \\
407.24+/-0.13\end{array}$ \\
\hline Multicrystaline Si & $\begin{array}{c}\text { VeraSol } \\
\text { Sol3A }\end{array}$ & $\begin{array}{l}9.47+/-0.077 \\
9.59+/-0.110\end{array}$ & $\begin{array}{l}0.602+/-0.0005 \\
0.598+/-0.0007\end{array}$ & $\begin{array}{l}252.4+/-0.2 \\
252.8+/-0.5\end{array}$ \\
\hline Thin Film CIGS & $\begin{array}{l}\text { VeraSol } \\
\text { Sol3A }\end{array}$ & $\begin{array}{l}14.63+/-0.04 \\
14.62+/-0.08\end{array}$ & $\begin{array}{l}0.642+/-0.0005 \\
0.639+/-0.0002\end{array}$ & $\begin{array}{l}13.10+/-0.01 \\
13.10+/-0.01\end{array}$ \\
\hline $\begin{array}{l}\text { Thin Film } \\
\text { amorphous Si } \\
\text { Module }\end{array}$ & $\begin{array}{l}\text { VeraSol } \\
\text { Sol3A }\end{array}$ & $\begin{array}{l}2.705+/-0.001 \\
2.700+/-0.002\end{array}$ & $\begin{array}{l}4.243+/-0.004 \\
4.216+/-0.007\end{array}$ & $\begin{array}{l}28.16+/-0.02 \\
28.09+/-0.04\end{array}$ \\
\hline
\end{tabular}

Table 1: IV curve parameters taken from each type of solar cell. Electrodes were repositioned for each IV curve and the standard error of the mean is reported from multiple experiments. 
However, the difference line, or residual, for each graph (grey line) does reveal a slight trend in which the curves taken from the Sol3A-xenon lamp reported a lower value near $\mathrm{V}_{\mathrm{oc}}$; this is not apparent from visual/statistical comparison of the $\mathrm{I}-\mathrm{V}$ curves. This trend is also seen in table 1, although all differences were within the measurement variability. It is common knowledge that heat rapidly reduces the $\mathrm{V}_{\text {oc }}$ and thus the performance of solar cells. Because this trend is observed in all solar cells tested and the phenomenon took place near $\mathrm{V}_{\mathrm{oc}}$, it suggests the shift is related to an enhanced temperature created by the Sol3A-xenon lamp that is not present with the VeraSol-LEDs. This temperature shift in the $\mathrm{V}_{\mathrm{oc}}$ was further considered later in the manuscript (Figure 11). Also, the VeraSol-LED data tends to have a lower variation about the mean from test to test than does the lamp-based simulator.

Although it is possible that results using other materials may reveal a more robust difference between the two light sources under matched $\mathrm{I}_{\mathrm{sc}}$ conditions, a significant difference was not detected in these tests suggesting the industry standard of $+/-25 \%$ over a $100 \mathrm{~nm}$ range is sufficient and useful for grading traditional solar simulators.

\section{Calculated Spectral Mismatch Factors}

Spectral differences between a solar simulator and AM1.5G will always provide some measurable difference. Considering the spectral response of each of the PV cells tested, the expected difference was calculated between AM1.5G and the two simulators tested in this study using equations shown in the Methods section: Spectral mismatch correction. The VeraSol-LED has a substantially lower mismatch factor to AM1.5G for 
all of the PV cells tested compared to that of the Sol3A xenon lamp, respectively: crystalline silicon (0.98 vs 1.10$)$, amorphous thin film (0.998 vs 1.14), and CIGS (0.992 vs 1.085$)$.

\section{Experimentally Measured Spectral Mismatch}

Both simulators were adjusted to 1 sun with the Newport calibrated, monocrystalline silicon PV cell (Oriel Part Number: 91150V). I-V responses were subsequently taken for the thin film, amorphous silicon module alternating between the Sol3A-xenon lamp and the VeraSol-LED. Between each I-V sweep the simulator one sun intensity was checked with the calibrated cell. The SR of the thin film was overlaid with the irradiance spectrum to clearly highlight which wavelengths of light are absorbed by this solar cell (Figure 10A). Because of the enhanced irradiance of the Sol3A-xenon lamp from 400-700, a significant mismatch was expected for these types of solar cells.

Figure 10B illustrates this dramatic mismatch that was measured in the I-V response for the Sol3A-xenon lamp $\left(\mathrm{I}_{\mathrm{sc}}=28.8 \mathrm{~mA}\right)$ compared to VeraSol-LED $\left(\mathrm{I}_{\mathrm{sc}}=25.1 \mathrm{~mA}\right)$. This corresponded to a $14.7 \%$ difference in measured $\mathrm{I}_{\mathrm{sc}}$ between the two simulators.

To adjust the response so it was equivalent to illumination at $\mathrm{AM} 1.5 \mathrm{G}$, the spectral mismatch factor was determined for both systems using the SR data for the thin film (Figure 7) and the spectral irradiance (Figure 8). The mismatch correction factor $\left(\mathrm{M}_{\text {VeraSol-LED }}\right)$ for the VeraSol-LED was

$$
M_{\text {VeraSol-LED }}=\frac{\int_{310}^{1100} S_{P V \text { cell }} * E_{\text {VeraSol }}}{\int_{310}^{1100} S_{P V \text { cell }} * E_{A M 1.5 G}}=1.000
$$



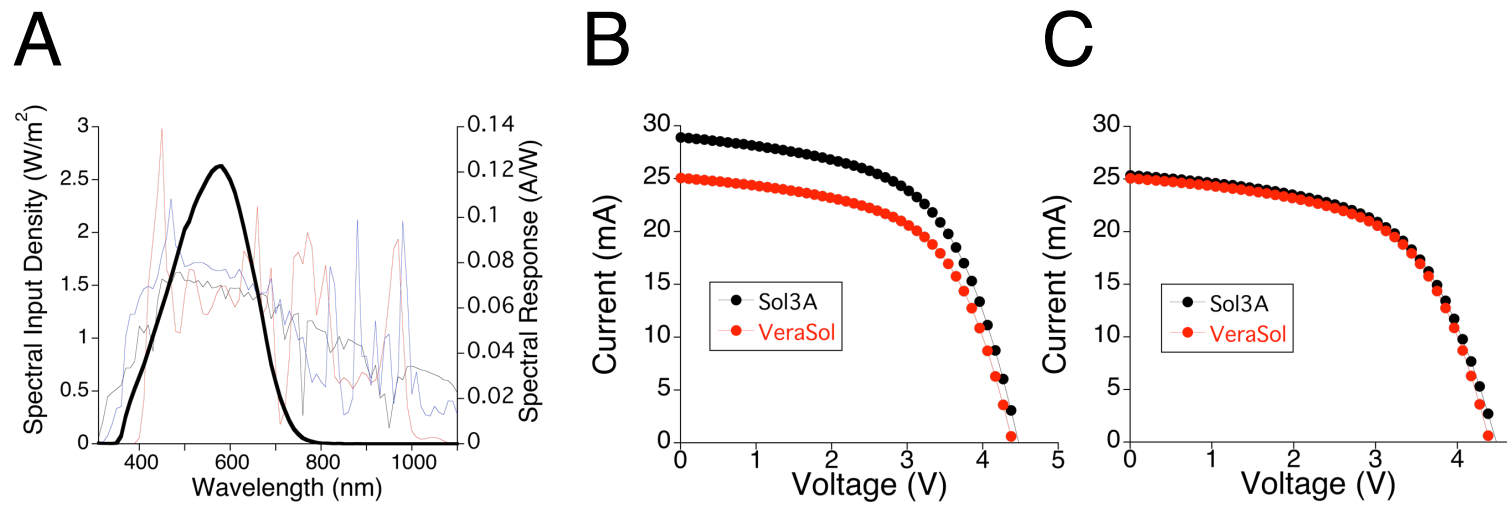

Figure 10: A. The spectral response of the amorphous silicon thin film module with background spectra for the VeraSol-LED (blue), Sol3A-xenon lamp (red), and AM1.5G (black). B. VeraSol-LED (red) and Sol3A-xenon lamp (black) IV curves from an amorphous silicon thin film module $\left(6.75 \mathrm{~cm}^{2}\right)$ at 1 sun. C. The AM1.5G mismatch correction factor applied to the VeraSol-LED (red) and Sol3A-xenon lamp (black) IV curves from Figure 4B. The mismatch correction factor was determined from the spectral response and solar irradiance.

and the mismatch correction factor for the Sol3A-xenon lamp was

$$
M_{\text {Sol } 3 A-x e n o n ~ l a m p}=\frac{\int_{310}^{1100} S_{P V \text { cell }} * E_{\text {Sol } 3 A}}{\int_{310}^{1100} S_{P V c e l l} * E_{A M 1.5 G}}=1.140 .
$$

The measured $14.7 \%$ difference corresponded well to $14 \%$ difference calculated above between the two simulators. Figure 10C shows the two corrected I-V curves considering the spectral mismatch correction factor; both curves converge near that of the VeraSolLED initial measurement.

\section{$\underline{\text { Solar Simulator Temperature Effects }}$}

Continuous one sun illumination of a crystalline silicon PV cell over 30 minutes did not shift the $\mathrm{V}_{\text {oc }}$ when illuminated with the VeraSol-LED solar simulator (Figure 11A). In contrast, the Sol3A xenon lamp-based simulator caused a left shift in I-V curve 

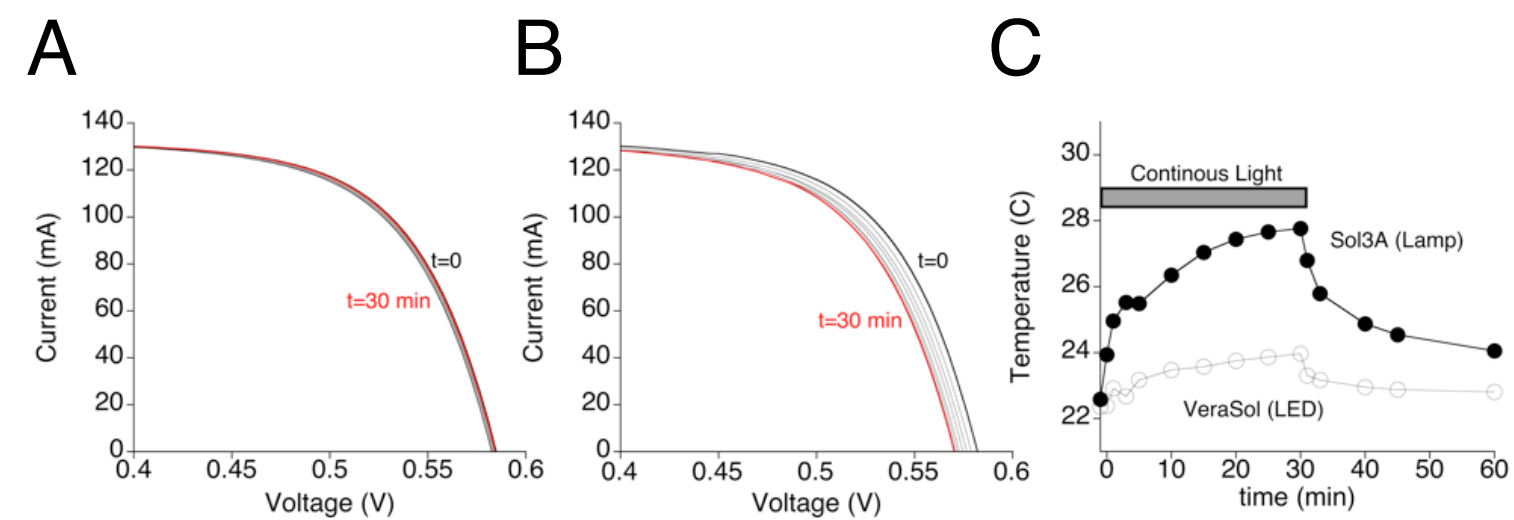

Figure 11: Minimal temperature artifacts associated with the VeraSol-LED A. IV Curves taken at 1, 3, 10,15, 20, 30 minutes under continuous 1 sun illumination for the VeraSol-LED (A) or Sol3A-xenon lamp (B). The 30 min time points are plotted in red and 0 min curve is plotted in black with subsequent curves plotted in gray. $\mathrm{C}$. PV cell temperature for the two experiments in A and B over the 30 minute light exposure as well as a 30 minute recovery with no light.

$\mathrm{V}_{\text {oc }}$ almost instantly (Figure 11B). This temperature change of the silicon PV wafer for both simulators is plotted in the Figure 11A inset. The apparent exponential rise and decay kinetics correspond to the heating of the entire test system (PV cell + Stage $)$ and should vary depending on the setup. In general, the VeraSol-LED simulator limits these unwanted heating components by excluding individual wavelengths outside the bandgap of a material. Although this may be desirable for some applications, the removable of wavelengths that are always present within the sun spectrum can arguably be detrimental for other experimental applications. 


\section{CONCLUSION}

Considering the comparisons in this paper, both simulators generate cell efficiently/performance measurements from a variety of PV devices as if the sun had illuminated them. The spectral differences between the VeraSol-LED and the Sol3Axenon lamp did not affect the gross properties of the I-V curve response for the PV cells when the $I_{s c}$ were matched (Figure 9). From this data, the conclusion is made that the qualification in matching total irradiance over the $100 \mathrm{~nm}$ sections is currently sufficient in matching the AM1.5G spectrum. Solar radiation beyond the bandgap of a material generates heat, and this heat has the additional effect of shifting the open circuit voltage $\left(\mathrm{V}_{\mathrm{oc}}\right)$ of the I-V curve. The increased heat associated with the Sol3a-xenon lamp may account for the slight deviation. This is supported by the 30 minute experiments conducted on a crystalline silicon PV cell in figure 5 in which the $\mathrm{V}_{\text {oc }}$ clearly shifts when illuminated with the Sol3A-xenon lamp but not the VeraSol-LED. The VeraSol-LED lacks both high intensity $(<400 \mathrm{~nm})$ and low intensity $(>1100 \mathrm{~nm})$ wavelength energy that is present within the solar spectrum. This lack of heat with the VeraSol could be considered either a benefit or detriment depending on ones experimental design. More recent efforts have been made to couple an LED simulator with a lamp source to further capture total solar spectrum $[35,36]$.

The VeraSol-LED simulator did a better job of resembling AM1.5G largely because of the flexibility in tuning the LED output spectrum. The total integration of AM1.5G (756 W/A) was almost identical to the irradiance of the VeraSol-LED (760 W/A), yet substantially different from that of the Sol3A-xenon lamp (818 W/A) over the 
same region (400-1100 nm). This accuracy, also, was demonstrated experimentally with an amorphous thin film solar cell under one sun illumination, shown in figure 2. Because the thin film has a bandgap at $\sim 750 \mathrm{~nm}$, the mismatch to AM1.5G for the xenon bulb was almost $15 \%$. Considering the aging problem of xenon arc lamps, this spectral mismatch factor can be a continually shifting target to define. Conversely, the VeraSolLED almost identically matched the AM1.5G energy over the active region of the amorphous thin film. Although this was a single example, the ability of the VeraSolLED to alter the output energy with a $30-50 \mathrm{~nm}$ resolution significantly aids in matching any desired response.

Currently the VeraSol-LED offers an equivalent if not better solar illumination between 400-1100 nm than the xenon lamp-based Sol3A. There were no discernable differences in the I-V response from a number of solar cells, and the flexibility to change and rapidly gate LEDs across the sun spectrum conferred a better match to AM1.5G. Future advancements to the VeraSol-LED simulator would truly make it superior to previous simulator technology. 1) Clearly the VeraSol-LED match to the sun is limited in wavelength beyond $1100 \mathrm{~nm}$. Closer matches to this spectral region will likely depend on the development of better LEDs that cover this regions of the solar spectrum. 2) Enhancing the intensity of the output to reach AM0 irradiance would significantly improve the instrument. Solar cell materials are developed for numerous terrestrial and space applications. Expanding the spectrum to shift between AM0 and AM1.5G would improve the versatility of the VeraSol-LED, and it applicability within individual research facilities. 3) Although the LEDs have an extended lifetime compared to lamp 
technology, it is uncertain how many times these LEDs will need recalibrating during this period to maintain this triple A rating. Incorporating a detailed self-calibrating spectral match and intensity system on startup may make this a long lasting, maintenance free solar simulator. 4) Finally, optical improvements to the design of the VeraSol-LED need to be considered to improve the loss in energy at $700 \mathrm{~nm}$. Although this is a small region of the solar spectrum, it is conceivable that a solar cell designed for this region of the spectrum could unexpectedly show a significant spectral mismatch that may confound data, similar to mismatch problems the Sol3A-xenon lamp had with the amorphous thin film solar cell. 


\section{REFERENCES CITED}

[1] E. Manke, Standards for Simulators Can Vary Wildly. Solar Industry, March 2010.

[2] K. A. Emery, "Solar simulators and I-V measurement methods," Solar Cells, vol. 18, no. 3, pp. 251-260, Sep. 1986.

[3] K. Emery, D. Myers, and S. Rummel, "Solar simulation-problems and solutions," in , Conference Record of the Twentieth IEEE Photovoltaic Specialists Conference, 1988, 1988, pp. 1087-1091 vol.2.

[4] R. A. Houghton, "The Contemporary Carbon Cycle," Treatise on Geochemistry, vol. 8, p. 682, Dec. 2003.

[5] R. Perez, K. Zweibel, and T. E. Hoff, "Solar power generation in the US: Too expensive, or a bargain?," Energy Policy, vol. 39, no. 11, pp. 7290-7297, Nov. 2011.

[6] N. S. Lewis, "Powering the Planet," MRS Bulletin, vol. 32, no. 10, pp. 808-820, Oct. 2007.

[7] M. A. Green, "The path to $25 \%$ silicon solar cell efficiency: History of silicon cell evolution," Prog. Photovolt: Res. Appl., vol. 17, no. 3, pp. 183-189, May 2009.

[8] M. Green, Third Generation Photovoltaics: Advanced Solar Energy Conversion. Springer Science \& Business Media, 2006.

[9] U. Gangopadhyay, S. Jana, and S. Das, "State of Art of Solar Photovoltaic Technology," Conference Papers in Energy, vol. 2013, pp. 1-9, 2013.

[10] G. Chidichimo, L. Filippelli, G. Chidichimo, and L. Filippelli, "Organic Solar Cells: Problems and Perspectives, Organic Solar Cells: Problems and Perspectives," International Journal of Photoenergy, International Journal of Photoenergy, vol. 2010, 2010, p. e123534, Jul. 2010.

[11] U. Mehmood, S. Rahman, K. Harrabi, I. A. Hussein, B. V. S. Reddy, U. Mehmood, S. Rahman, K. Harrabi, I. A. Hussein, and B. V. S. Reddy, "Recent Advances in Dye Sensitized Solar Cells, Recent Advances in Dye Sensitized Solar Cells," Advances in Materials Science and Engineering, Advances in Materials Science and Engineering, vol. 2014, 2014, p. e974782, Apr. 2014. 
[12] M. I. Ahmed, A. Habib, S. S. Javaid, M. I. Ahmed, A. Habib, and S. S. Javaid, "Perovskite Solar Cells: Potentials, Challenges, and Opportunities, Perovskite Solar Cells: Potentials, Challenges, and Opportunities," International Journal of Photoenergy, International Journal of Photoenergy, vol. 2015, 2015, p. e592308, Oct. 2015.

[13] A. J. Nozik, "Nanoscience and Nanostructures for Photovoltaics and Solar Fuels," Nano Lett., vol. 10, no. 8, pp. 2735-2741, Aug. 2010.

[14] R. Liu, "Hybrid Organic/Inorganic Nanocomposites for Photovoltaic Cells," Materials, vol. 7, no. 4, pp. 2747-2771, Apr. 2014.

[15] NREL (2016, Feb 25). Research cell efficiency records. Retrieved from http://www.nrel.gov/ncpv/.

[16] M. Thirugnanasambandam, S. Iniyan, and R. Goic, "A review of solar thermal technologies," Renewable and Sustainable Energy Reviews, vol. 14, no. 1, pp. 312322, Jan. 2010.

[17] M. Hamid Elsheikh, D. A. Shnawah, M. F. M. Sabri, S. B. M. Said, M. Haji Hassan, M. B. Ali Bashir, and M. Mohamad, "A review on thermoelectric renewable energy: Principle parameters that affect their performance," Renewable and Sustainable Energy Reviews, vol. 30, pp. 337-355, Feb. 2014.

[18] K. Biswas, J. He, I. D. Blum, C.-I. Wu, T. P. Hogan, D. N. Seidman, V. P. Dravid, and M. G. Kanatzidis, "High-performance bulk thermoelectrics with all-scale hierarchical architectures," Nature, vol. 489, no. 7416, pp. 414-418, Sep. 2012.

[19] D. Kraemer, B. Poudel, H.-P. Feng, J. C. Caylor, B. Yu, X. Yan, Y. Ma, X. Wang, D. Wang, A. Muto, K. McEnaney, M. Chiesa, Z. Ren, and G. Chen, "Highperformance flat-panel solar thermoelectric generators with high thermal concentration," Nat Mater, vol. 10, no. 7, pp. 532-538, Jul. 2011.

[20] A. Date, A. Date, C. Dixon, and A. Akbarzadeh, "Progress of thermoelectric power generation systems: Prospect for small to medium scale power generation," Renewable and Sustainable Energy Reviews, vol. 33, pp. 371-381, May 2014.

[21] N. Miljkovic and E. N. Wang, "Modeling and optimization of hybrid solar thermoelectric systems with thermosyphons," Solar Energy, vol. 85, no. 11, pp. 2843-2855, Nov. 2011.

[22] P. Sundarraj, D. Maity, S. S. Roy, and R. A. Taylor, "Recent advances in thermoelectric materials and solar thermoelectric generators - a critical review," RSC Adv., vol. 4, no. 87, pp. 46860-46874, Sep. 2014. 
[23] H. B. Gray, "Powering the planet with solar fuel," Nat Chem, vol. 1, no. 1, pp. 7-7, Apr. 2009.

[24] O. Inganäs and V. Sundström, "Solar energy for electricity and fuels," Ambio, vol. 45, no. Suppl 1, pp. 15-23, Jan. 2016.

[25] D. G. Nocera, “The Artificial Leaf," Acc. Chem. Res., vol. 45, no. 5, pp. 767-776, May 2012.

[26] Rhode, R. (2007, Jun 9). Solar Specturm. Global Warming Art. Retrieved from https://commons.wikimedia.org/wiki/File:Solar_Spectrum.png

[27] D. Kolberg, F. Schubert, N. Lontke, A. Zwigart, and D. M. Spinner, "Development of tunable close match LED solar simulator with extended spectral range to UV and IR," Energy Procedia, vol. 8, pp. 100-105, 2011.

[28] T. R. B. M. Bliss, "Advantages in using LEDs as the main light source in solar simulators for measuring PV device characteristics," Proceedings of SPIE - The International Society for Optical Engineering, vol. 7048, 2008.

[29] R. J. Matson, K. A. Emery, and R. E. Bird, "Terrestrial solar spectra, solar simulation and solar cell short-circuit current calibration: A review," Solar Cells, vol. 11, no. 2, pp. 105-145, Mar. 1984.

[30] Davidson, MW. Fundamentals of Xenon Arc Lamps. Retrieved from http://zeisscampus.magnet.fsu.edu/articles/lightsources/xenonarc.html.

[31] Oriel Product Training. Solar Simulation. Newport. Retrived from https://assets.newport.com/webDocuments-EN/images/12298.pdf

[32] S. H. Jang and M. W. Shin, "Fabrication and thermal optimization of LED solar cell simulator," Current Applied Physics, vol. 10, no. 3, Supplement, pp. S537-S539, May 2010.

[33] K. Emery, D. Dunlavy, H. Field, and T. Moriarty, "Photovoltaic spectral responsivity measurements," National Renewable Energy Lab., Golden, CO (United States), 1998.

[34] O’Donnell M., The spectral Mismatch Factor. Application Note 51, Newport Corporation, 2013.

[35] Y. Tsuno, Koichi Kamisako, and K. Kurokawa, "New generation of PV module rating by LED solar simulator - A novel approach and its capabilities," in 33rd 
IEEE Photovoltaic Specialists Conference, 2008. PVSC ’08, 2008, pp. 1-5.

[36] W. Wang and B. Laumert, Simulate a "Sun" for Solar Research: A Literature Review of Solar Simulator Technology. KTH Royal Institute of Technology, 2014.

[37] S. Kohraku and K. Kurokawa, "A fundamental experiment for discrete-wavelength LED solar simulator," Solar Energy Materials and Solar Cells, vol. 90, no. 18-19, pp. 3364-3370, Nov. 2006.

[38] G. Grandi and A. Ienina, "Analysis and realization of a low-cost hybrid LEDhalogen solar simulator," in 2013 International Conference on Renewable Energy Research and Applications (ICRERA), 2013, pp. 794-799.

[39] K. A. Kim, N. Dostart, J. Huynh, and P. T. Krein, "Low-cost solar simulator design for multi-junction solar cells in space applications," in Power and Energy Conference at Illinois (PECI), 2014, 2014, pp. 1-6.

[40] S. Kohraku and K. Kurokawa, "New methods for solar cells measurement by LED solar simulator," in Proceedings of 3rd World Conference on Photovoltaic Energy Conversion, 2003, 2003, vol. 2, pp. 1977-1980 Vol.2.

[41] A. Mohammad Bagher, "Types of Solar Cells and Application," American Journal of Optics and Photonics, vol. 3, no. 5, p. 94, 2015.

[42] "Photovoltaics Report". 2014, July 28. Fraunhofer ISE. Retrived from https://www.ise.fraunhofer.de/en/news/news-archive/news-2012/fraunhofer-isepublishes-photovoltaics-report. 
APPENDIX A

IQE 200 Operations Manuel 


\section{IQE 200 Operations Manual}

\section{IQE/EQE/SR Measurement}

1. Turn on IQE-200 Power Switch located on the front panel.

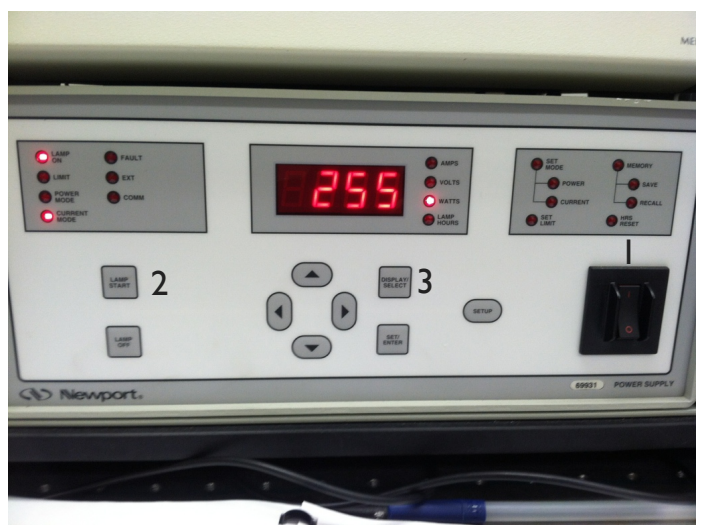

2. Press the Lamp Start button.

3. Display/select can be used to toggle the control and then press Set/Enter to alter the wattage and use arrows to obtain desired power value (255 Watts).

4. Click on IQE200 icon to open the IQE200 software on the laptop.

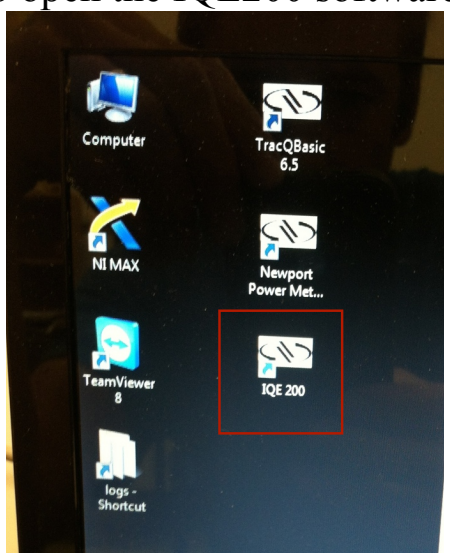

5. Prepare the sample on the copper plate making contact to the top of the wafer. 
6. Connect the positive (black in next picture to copper ground) and negative leads

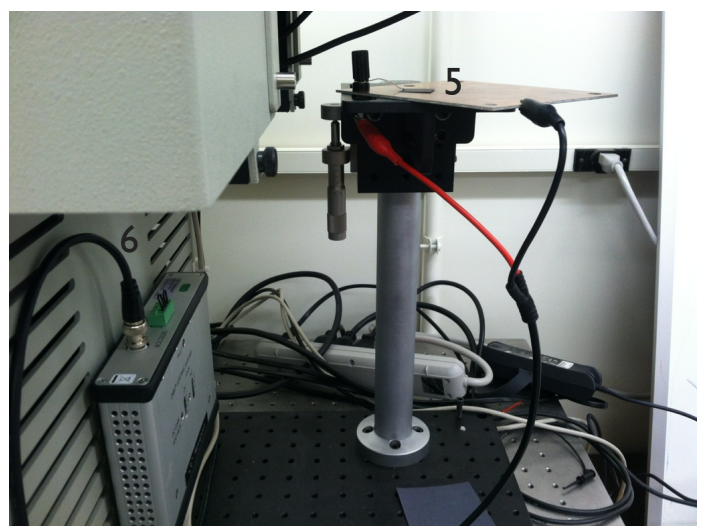

(red in next picture to top of PV cell) via BNC cable to the IQE200.

7. Select Go To in the software and change the wavelength to $555 \mathrm{~nm}$ and select Go, which will move the monochrometer to a visible, green, rectangular beam on the output of the IQE 200. You may need to use a black sheet of paper held over the platform to see the beam. This will allow you to position your solar cell so that the light source is not being blocked by a bus bar and is properly positioned on

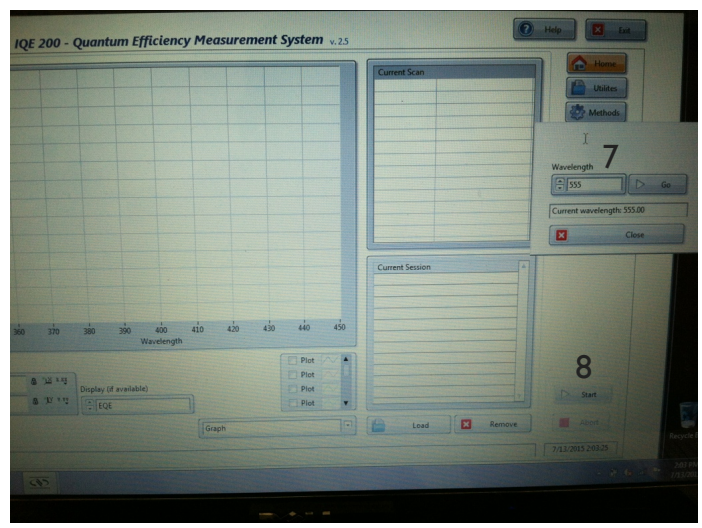

your sample. Close the the small pop up window

8. Press Start.

9. A window should appear where you can deselect auto save (a), type your file (b),

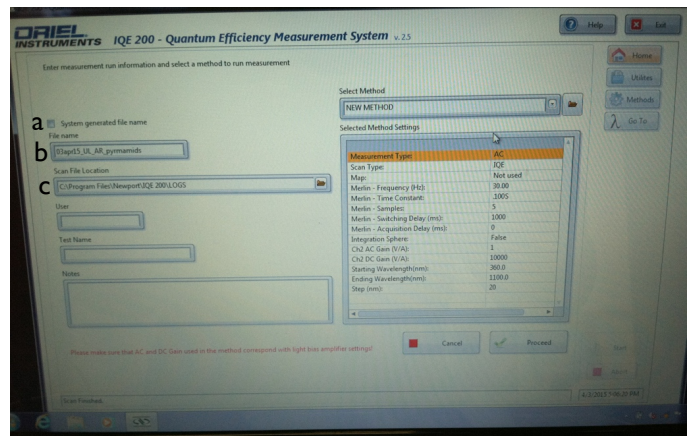

and direct the location to save your file (c). 
10. Choose a method from the drop down menu: simple IQE takes measurements from Channel 1, Channel 2, and Channel 3 to measure the Quantum efficiency plus the reflectance from the sample. The parameters for simple IQE are listed in

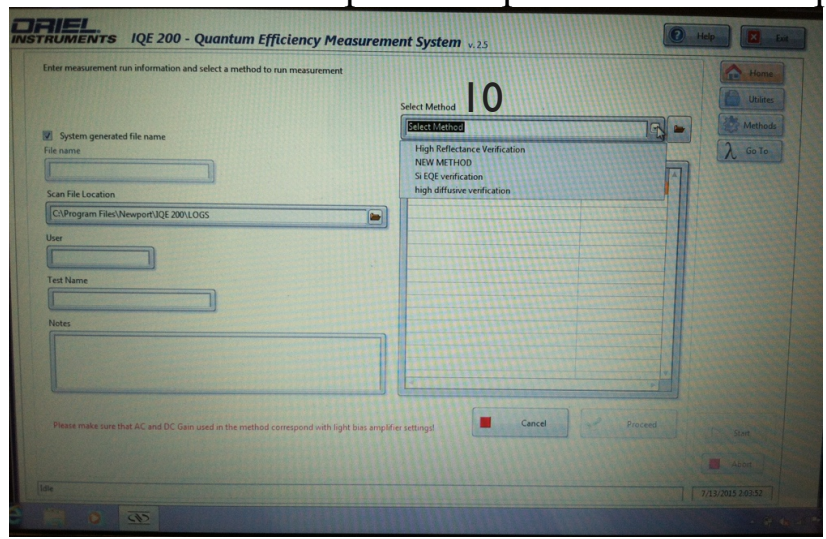

the table below the menu.

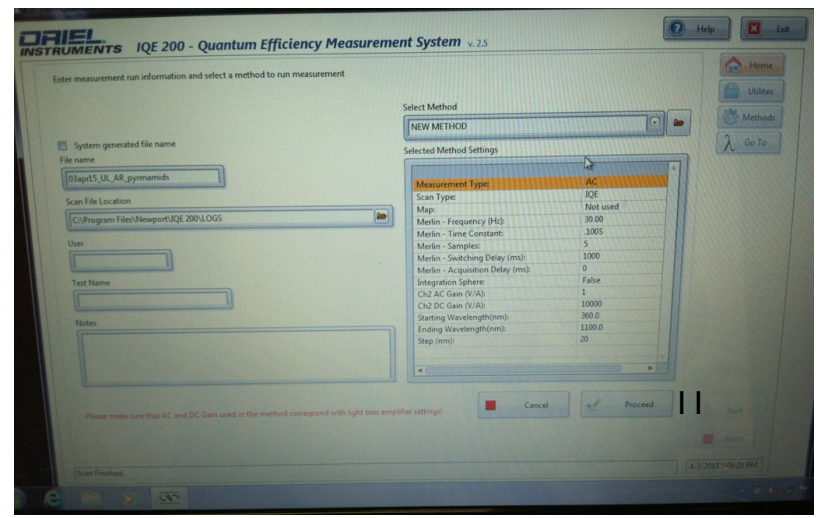

11. Select Proceed to begin recording. The recording will take between 5-10 min to create a full spectrum.

12. Under the Display you can select which plot you wish to observe (Spectral response, EQE, IQE, (if available)) and

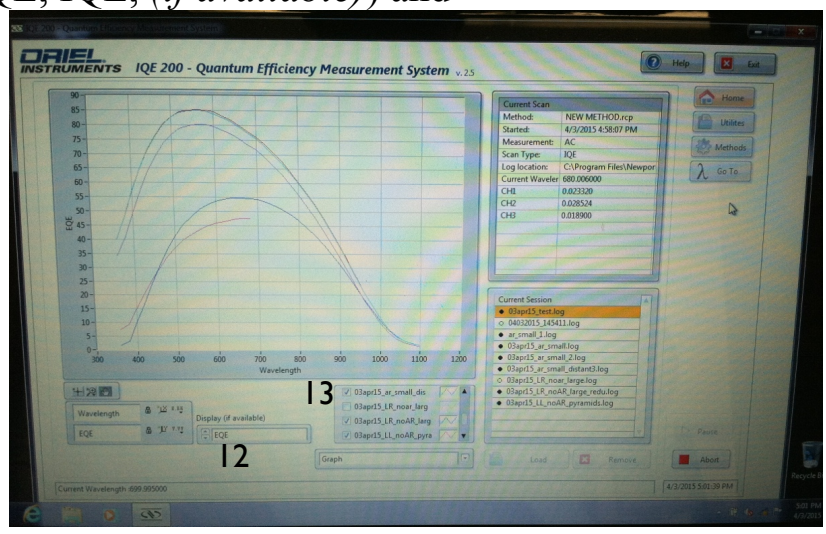

13. You can add previous plots by checking boxes. 
14. Test each of the 4 cells from $360-1100 \mathrm{~nm}(10-20 \mathrm{~nm})$ steps. The files are saved as .log files but this can be replaced with a txt and opened on either PC or Mac. Curves should be overlaid in Excel or Matlab for comparison.

15. From each curve you should be able to calculate the expect short circuit current at AM1.5G and compare it with your I-V curves. (equation)

16. Too Shut down. Close software on computer; then turn lamp off on front panel; finally turn power switch to off.

\section{EQE Calibration}

1. Turn on lamp and let it warm up for 20-30min.

2. Select Utilities and in the upper right choose EXT QE Calibration form the drop down menu; a calibration wizard will provide additional steps to follow that complement instructions below.

3. Position the calibrated silicon reference device on the sample and adjust the height so it is focused at the surface. Also connect the BNC into the light amplifier.

4. Load the Si detector responsivity file. Click on the folder icon and navigate to the responsivity file (C:/program files/Newport/IQE 200/configuration/calibration standards and is labeled IQE-Sample-Si.... (click accept and next). The scan should cover $360 \mathrm{~nm}$ to $1100 \mathrm{~nm}$.

5. The instrument will scan with $10 \mathrm{~nm}$ wavelengths over the detector

6. Click accept if satisfied with output

\section{Spectral Reflectance Calibration}

1. Turn on lamp and let it warm up for 20-30min.

2. Position the low reflectance standard (black glass FSQ-OD400 case) on the sample location with the printed glass model number facing up. Focus the light at $555 \mathrm{~nm}$ on the surface using a black piece of paper just above the sample to observe the light.

3. Select Utilities and in the upper right choose RS Calibration from the drop down menu; a calibration wizard will provide additional steps to follow that complement instructions below.

4. Load the low reflectance file. Click on the folder icon and navigate to the responsivity file (C:/program files/Newport/IQE 200/configuration/calibration standards and is labeled \#g low reflectance.... (click accept and next). The scan should cover $360 \mathrm{~nm}$ to $1100 \mathrm{~nm}$.

5. When finished, choose next and the monochrometer will position the light to $555 \mathrm{~nm}$ to load the high reflectance sample

6. Position the high reflectance standard (mirror 20D20Al.2)) on the sample location with the printed glass model number facing up. Focus the light at $555 \mathrm{~nm}$ on the surface. 
Load the high reflectance file. Click on the folder icon and navigate to the responsivity file (C:/program files/Newport/IQE 200/configuration/calibration standards and is labeled \#g high reflectance.... (click accept and next). The scan should cover $360 \mathrm{~nm}$ to 1100 nm. 